NBER WORKING PAPER SERIES

INNOVATION AND THE FINANCIAL GUILLOTINE

\author{
Ramana Nanda \\ Matthew Rhodes-Kropf \\ Working Paper 19379 \\ http://www.nber.org/papers/w19379
}

NATIONAL BUREAU OF ECONOMIC RESEARCH
1050 Massachusetts Avenue
Cambridge, MA 02138
August 2013

We thank Gustavo Manso, Josh Lerner, Thomas Hellmann, Michael Ewens, Bill Kerr, Serguey Braguinsky, Antoinette Schoar, Bob Gibbons and Marcus Opp as well as seminar participants at CMU and MIT for fruitful discussion and comments. All errors are our own. The views expressed herein are those of the authors and do not necessarily reflect the views of the National Bureau of Economic Research.

NBER working papers are circulated for discussion and comment purposes. They have not been peerreviewed or been subject to the review by the NBER Board of Directors that accompanies official NBER publications.

(C) 2013 by Ramana Nanda and Matthew Rhodes-Kropf. All rights reserved. Short sections of text, not to exceed two paragraphs, may be quoted without explicit permission provided that full credit, including $\odot$ notice, is given to the source. 
Innovation and the Financial Guillotine

Ramana Nanda and Matthew Rhodes-Kropf

NBER Working Paper No. 19379

August 2013

JEL No. G24,G39,O31

\begin{abstract}
Our paper demonstrates that while failure tolerance by investors may encourage potential entrepreneurs to innovate, financiers with investment strategies that tolerate early failure endogenously choose to fund less radical innovations. Failure tolerance as an equilibrium price that increases in the level of experimentation. More experimental projects that don't generate enough to pay the price cannot be started. In equilibrium all competing financiers may choose to offer failure tolerant contracts to attract entrepreneurs, leaving no capital to fund the most radical, experimental projects. The tradeoff between failure tolerance and a sharp guillotine helps explain when and where radical innovation occurs.
\end{abstract}

\author{
Ramana Nanda \\ Harvard Business School \\ Rock Center 317 \\ Boston \\ MA 02163 \\ rnanda@hbs.edu \\ Matthew Rhodes-Kropf \\ Harvard Business School \\ Rock Center 313 \\ Soldiers Field \\ Boston, MA 02163 \\ and NBER \\ mrhodeskropf@hbs.edu
}




\section{Innovation and the Financial Guillotine}

Investors, corporations and even governments who fund innovation must decide which projects to finance and when to withdraw their funding in order to create the most value. A key insight from recent work is that a tolerance for failure may be extremely important for innovation as it makes agents more willing to take risks and to undertake exploratory projects that lead to innovation Holmstrom (1989), Aghion and Tirole (1994) and Manso (2011). Agents penalized for early failure are less willing to experiment. Similarly Stein (1989) argues that managers must be protected from short term financial reactions in order to encourage them to make long-run investments. ${ }^{1}$

The optimal level of failure tolerance, of course, varies from project to project. Yet, in many instances, a project-by-project optimization is not feasible. For example, a government looking to stimulate innovation may pass laws making it harder to fire employees. This level of 'failure tolerance' will apply to all employees, regardless of the projects they are working on. Similarly, a CEO with a long-term, 'failure tolerant' employment contract may take on many different types of projects. In fact, organizational structure, organizational culture, or a desire by investors to build a consistent reputation as entrepreneur friendly all result in firm-level policies towards failure tolerance. Put differently, the principal often has an 'innovation strategy' that is set ex ante - one that is a blanket policy that covers all projects in the principal's portfolio - and hence may not be optimal for every one of the projects. How does this financing strategy impact innovation? This is an important question because the answer inverts how we think about the impact of failure tolerance.

In this paper we depart from the prior literature that has looked at the optimal solu-

\footnotetext{
${ }^{1}$ A number of empirical papers consider the impact of policies that reduce managerial myopia and allow managers to focus on long-run innovation (Burkart, Gromb and Panunzi (1997), Myers (2000), Acharya and Subramanian (2009) , Ferreira, Manso and Silva (2011), Aghion, Reenen and Zingales (2009)).
} 
tion for individual projects, and instead consider the ex ante strategic choice of a firm, investor or government looking to maximize profits or promote innovation. We examine how different strategies impact the types of projects that an investor is willing to finance, and how this may impact the nature of innovation that will be undertaken across different types of firms and regions.

In particular, we highlight a central trade-off faced by principals when they pick their innovation strategy. A strategy that is more failure tolerant may encourage the agent to innovate, but simultaneously destroys the value of the real option to abandon the project. In the real options literature (Gompers (1995), Bergemann and Hege (2005), Bergemann, Hege and Peng (2008)), innovation is achieved through experimentation - several novel ideas can be tried and only those that continue to produce positive information should continue to receive funding. This idea has motivated the current thrust by several venture capital investors to fund the creation of a "minimum viable product" in order to test new entrepreneurial ideas as quickly and cheaply as possible, to 'kill fast and cheap', and only commit greater resources to improve the product after seeing early success. ${ }^{2}$

Thus, a failure tolerant policy has two effects: it stimulates innovation which creates value but destroys the value of the abandonment option. Put differently, a failure tolerant strategy increases the entrepreneur's willingness to experiment but decreases the investors willingness to fund experimentation.

We show that financiers who are more tolerant of early failure endogenously choose to fund less radical innovations, or ones where the value of abandonment options is low. This is because although entrepreneurs prefer a failure tolerant investor, in equilibrium, failure

\footnotetext{
${ }^{2}$ Venture capital investors seem to have sharp ready guillotines - Sahlman (1990), Hellmann (1998); Gompers and Lerner (2004) document the myriad control rights negotiated in standard venture capital contracts that allow investors to fire management and/or abandon the project. In fact, Hall and Woodward (2010) document that about $50 \%$ of the venture-capital backed startups in their sample had zero-value exits. Hellmann and Puri (2002) and Kaplan, Sensoy and Stromberg (2009) show that of the firms that are 'successful', many end up with CEOs who are different from the founders.
} 
tolerance has a price. The most radical projects cannot afford to pay the price. Thus, the most radical innovations are either not funded at all, or are endogenously funded by financiers who have a sharp financial guillotine. ${ }^{3}$ In fact, we show that principals have to be careful, since a strategy of being failure tolerant to promote innovation may have exactly the opposite effect than the one desired, leading to the funding of less radical innovation.

We also demonstrate that an equilibrium can arise in which all competing financiers choose to be failure tolerant in the attempt to attract entrepreneurs and thus no capital is available to fund the most radical innovations, even if there are entrepreneurs who want to find financing for such projects. This equilibrium becomes more likely to form when entrepreneurs on average have a greater desire for failure tolerance such as is thought to occur, for example, in parts of Europe and Japan (see Landier $(2002)^{4}$ ). Moreover, the equilibrium with all failure tolerant investors may be self-fulfilling if the act of shutting down more projects reduces the stigma attached to failure.

Our model therefore highlights that the type of innovation undertaken in an economy may depend critically on the institutions that either facilitate or hinder the ability to terminate projects at an intermediate stage, as well as cultural or institutional factors that determine the outside options for entrepreneurs. The institutional funding environment for innovation is an endogenous equilibrium outcome that may result in places or times with no investors able to fund radical innovation.

This paper is related to prior work examining the role of principal agent relationships in the innovation process (e.g. Holmstrom (1989), Aghion and Tirole (1994), Hellmann and Thiele (2011) and Manso (2011)) as well as how the principle agent problem influences

\footnotetext{
${ }^{3}$ Our model also demonstrates that some radical innovations can only be commercialized by investors who are not concerned with making NPV positive investments, such as for example, government funded initiates like the manhattan project or the lunar landing.

${ }^{4}$ In Landier (2002) the stigma of failure prevents entrepreneurs from abandoning bad projects.
} 
the decision to stop funding projects (e.g. Bergemann and Hege (2005), Cornelli and Yosha (2003) and Hellmann (1998)). We build on this work by considering the type of project an investor is willing to fund given their strategy (due to ability or willingness) to end the project at an intermediate stage. Our work is also related to research examining how incentives stemming from organizational structure can drive innovation (e.g. Qian and Xu (1998), Gromb and Scharfstein (2002), Fulghieri and Sevilir (2009)) and how the "soft budget constraint" problem drives the selection of projects (e.g. Roberts and Weitzman (1981) and Dewatripont and Maskin (1995)). We look specifically at innovation as an outcome and examine how these factors impact the degree to which investors choose to fund radical innovation. Finally, a recent group of empirical papers have looked for and found a positive effect of failure tolerance on the margin (e.g. Lerner and Wulf (2007), Azoulay, Zivin and Manso (2011), Acharya and Subramanian (2009), Ferreira, Manso and Silva (2011), Aghion, Reenen and Zingales (2009), Tian and Wang (2012), Chemmanur, Loutskina and Tian (2012)). Our ideas are consistent with these findings, although different from past theoretical work, as our point is that strategies that reduce short term accountability and thus encourage innovation on the intensive margin may simultaneously alter what financial backers are willing to fund and thus reduce innovation at the extensive margin. Examining this latter effect seems to be a fruitful avenue for further empirical research. ${ }^{5}$

The tradeoff we explore also has implications for a wider array of situations than just R\&D. In the context of a board choosing a CEO, the intuition presented here suggests that boards that provide long term contracts with more tolerance for failure may find that they then choose a more experienced CEO who is a more known commodity. A board

\footnotetext{
${ }^{5}$ Recent work by Ewens and Fons-Rosen (2013) and Cerqueiro et al. (2013) have found initial support for the the idea that failure tolerance may encourage innovation at the intensive margin but discourage it at the extensive margin.
} 
that makes it easy to fire the CEO is more likely to experiment by hiring a younger, less experienced CEO whose quality is less certain but whose potential may be great. Thus, the same result occurs in this context - the desire to alter the intensive margin for innovation alters the extensive margin in the willingness to select a more radical leader.

The remainder of the paper is organized as follows. Section I develops a model of investing in innovative projects from both the financier's and entrepreneur's point of view. Section II solves for the deal between the financier and entrepreneur for different types of projects and levels of commitment. Section III determines the choices of the entrepreneur and investor given their level of commitment and desire for a committed investor. Section IV endogenizes the choice of failure tolerance by the investor and determines the potential equilibria and how they depend on the the view of early failure in the labor market and by the entrepreneur. Section V discusses the key implications and extensions of our model and Section VI concludes.

\section{A Model of Investment}

We model the creation of new projects that need an investor and an entrepreneur in each of two periods. Both the investor and entrepreneur must choose whether or not to start a project and then, at an interim point, whether to continue the project.

This basic set up is a two-armed bandit problem. There has been a great deal of work modeling innovation that has used some from of the two armed bandit problem. From the classic works of Weitzman (1979), Roberts and Weitzman (1981), Jensen (1981), Battacharya, Chatterjee and Samuelson (1986) to more recent works such as Moscarini and Smith (2001), Manso (2011) and Akcigit and Liu (2011). ${ }^{6}$ We build on this work by altering features of the problem to explore an important dimension in the decision to fund

\footnotetext{
${ }^{6}$ See Bergemann and Valimaki (2006) for a review of the economics literature on bandit problems.
} 
innovation.

\section{A. Investor View}

We model investment under uncertainty. A penniless entrepreneur seeks funding from investors for a risky project that requires capital for two periods or stages. The first stage of the project reveals information about the probability of success in the second stage. ${ }^{7}$ The probability of 'success' (positive information) in the first stage is $p_{1}$ and reveals the information $S$, while 'failure' reveals $F$. Success in the second stage yields a payoff of $V_{S}$ or $V_{F}$ depending on what happened in the first stage, but occurs with a probability that is unknown and whose expectation depends on the information revealed by the first stage. Failure in the second stage yields a payoff of zero.

Let $E\left[p_{2}\right]$ denote the unconditional expectation about the second stage success. The investor updates their expectation about the second stage probability depending on the outcome of the first stage. Let $E\left[p_{2} \mid S\right]$ denote the expectation of $p_{2}$ conditional on success in the first stage, while $E\left[p_{2} \mid F\right]$ denotes the expectation of $p_{2}$ conditional on failure in the first stage. ${ }^{8}$

The project requires capital $X$ to complete the first stage of the project and $Y$ to complete the second stage. The entrepreneur is assumed to have no capital while the investor has enough to fund the project for both periods. An investor who chooses not to invest at either stage can instead earn a safe return of $r$ per period (investor outside option) on either $X, Y$ or both. We assume project opportunities are time sensitive, so if the project is not funded at either the 1st or 2nd stage then it is worth nothing.

\footnotetext{
${ }^{7}$ This might be the building of a prototype or the FDA regulated Phase I trials on the path of a new drug. Etc.

${ }^{8}$ One particular functional form that is sometimes used with this set up is to assume that the first and second stage have the same underlying probability of success, $p$. In this case $p_{1}$ can be thought of as the unconditional expectation of $p$, and $E\left[p_{2} \mid S\right]$ and $E\left[p_{2} \mid F\right]$ just follow Bayes' rule. We use a more general setup to express the idea that the probability of success of the first stage experiment is potentially independent of the amount of information revealed by the experiment. For example, there could be a project for which a first stage experiment would work with a $20 \%$ chance but if it works the second stage is almost certain to work ( $99 \%$ probability of success).
} 
In order to focus on the interesting cases we assume that if the project 'fails' in the first period then it is NPV negative in the second period, i.e., $E\left[p_{2} \mid F\right] * V_{F}<Y(1+r)$. And if the project 'succeeds' in the first period then it is NPV positive in the second period, i.e., $E\left[p_{2} \mid S\right] * V_{S}>Y(1+r)$. We will consider how variation in the probabilities alters the decision to fund the project.

We assume that principals/investors cannot commit to a long-term contract with the agent/entrepreneur at the beginning of the project. Prior work has assumed an idealized investor who can write long-term contracts allowing them to commit to some projects and not to others. Our departure from this work allows us to compare investors who can never commit to committed investors introduced in the next section. With limited commitment, the principal and the agent may agree on and bind themselves to short-term (one period) contracts, but cannot commit themselves to any future contracts. Investors in new projects are often unable to commit to fund the project in the future even if they desire to make such a commitment. For example, corporations cannot write contracts with themselves and thus always retain the right to terminate a project. Venture capital investors have strong control provisions for many standard incomplete contracting reasons and are unable to give up the power to shut down the firm and return any remaining money if they wish to do so in the future. Thus, even a project that receives full funding (both $\mathrm{X}$ and $\mathrm{Y}$ ) in the first period, may be shut down and $\mathrm{Y}$ returned to investors in period two.

We will demonstrate that the equilibrium fraction owned by the investor in the final period, assuming an agreement can be reached for investment in both periods, depends on the outcome of the first period. Let $\alpha_{S}$ represent the final fraction owned by the investors if the first period was a success, and let $\alpha_{F}$ represent the final fraction owned by the investors if the first period was a failure. 
The extensive form of the game played by the investor (assuming the entrepreneur is willing to start and continue the project) is shown in figure 1. Remember that by choosing not to invest in the project in either period the investor earns a return of $r$ per period on the money he does not invest in the risky project. We assume investors make all decisions to maximize net present value (which is equivalent to maximizing end of second period wealth).

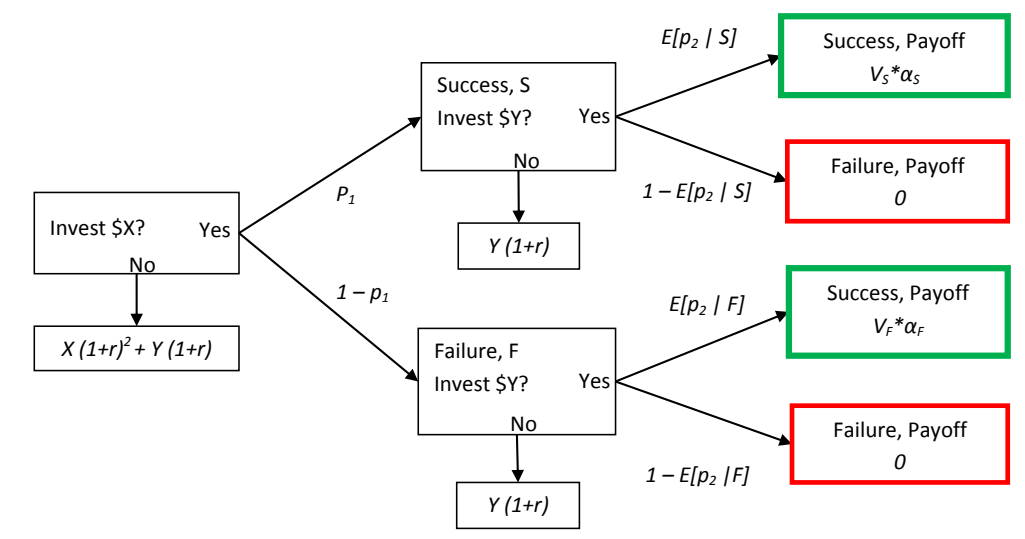

Figure 1. Extensive Form Representation of the Investor's Game Tree

\section{B. Entrepreneur's View}

Potential entrepreneurs are endowed with a project in period one with a given $p_{1}, p_{2}$, $E\left[p_{2} \mid S\right], E\left[p_{2} \mid F\right], V_{S}, V_{F}, X$ and $Y$. Assuming that an investor chooses to fund the first period of required investment, the potential entrepreneur must choose whether or not to become an entrepreneur or take an outside employment option. If the investor is willing to fund the project in the second period then the entrepreneur must choose whether or not to continue as an entrepreneur. If the potential entrepreneur chooses entrepreneurship and stays an entrepreneur in period 2 they generate utility of $u_{E}$ in both periods. Alternatively, if they choose not to become an entrepreneur in the first period then we assume that no entrepreneurial opportunity arises in the second period so they generate utility of $u_{O}$ in 
both periods. ${ }^{9}$

If the investor chooses not to fund the project in the second period, or the entrepreneur chooses not to continue as an entrepreneur, i.e., the entrepreneur cannot reach an agreement with an investor in period 2, then the project fails and the entrepreneur generates utility $u_{F}$ from their outside option in the second period. We assume $\Delta u_{F}=u_{F}-u_{E}<0$, which represents the disutility felt by a failed entrepreneur. The more negative $\Delta u_{F}$ is, the worse entrepreneurial experience in a failed project is perceived. ${ }^{10}$

Given success or failure in the first period the entrepreneur updates their expectation about the probability the project is a success just as the investor does. The extensive form of the game played by the entrepreneur (assuming funding is available) is shown in figure 2. We assume entrepreneurs make all decisions to maximize the sum of total utility.

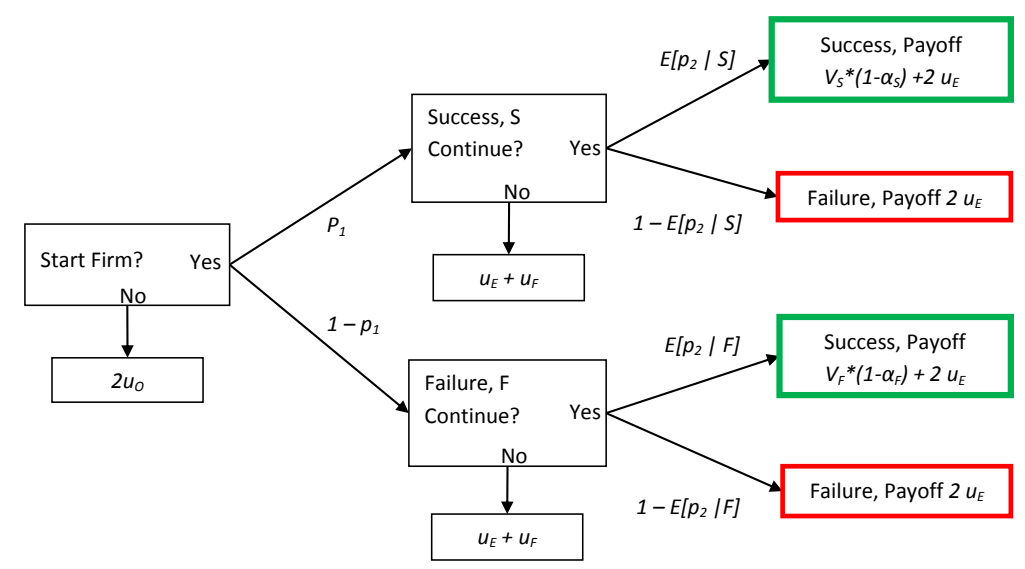

Figure 2. Extensive Form Representation of the Entrepreneur's Game Tree

\footnotetext{
${ }^{9}$ The entrepreneur could also receive side payments from the investor. This changes no results and so is suppressed.

${ }^{10}$ Entrepreneurs seem to have a strong preference for continuation regardless of present-value considerations, be it because they are (over)confident or because they rationally try to prolong the search. Cornelli and Yosha (2003) suggest that entrepreneurs use their discretion to (mis)represent the progress that has been made in order to secure further funding.
} 


\section{The Deal Between the Entrepreneur and Investor}

In this section we determine when the entrepreneur and investors will be able to find an acceptable deal. We do so by determining the minimum share both the entrepreneur and investor must own in order to choose to start the project.

The final fraction owned by investors after success or failure in the first period, $\alpha_{j}$ where $j \in\{S, F\}$, is determined by the amount the investors purchased in the first period, $\alpha_{1}$, and the second period $\alpha_{2 j}$, which may depend on the outcome in the first stage. Since the first period fraction gets diluted by the second period investment, $\alpha_{j}=\alpha_{2 j}+\alpha_{1}\left(1-\alpha_{2 j}\right)$.

\section{A. No Commitment}

Using backward induction we start with the second period. Conditional on a given $\alpha_{1}$ the investor will invest in the second period as long as

$$
V_{j} \alpha_{j} E\left[p_{2} \mid j\right]-Y(1+r)>0 \quad \text { where } j \in\{S, F\}
$$

This condition does not hold after failure even if $\alpha_{F}=1$, therefore the investor will only invest after success in the first period. The minimum fraction the investor is willing to accept for an investment of $Y$ in the second period after success in the first period is

$$
\underline{\alpha_{2 S}}=\frac{Y(1+r)}{V_{S} E\left[p_{2} \mid S\right]}
$$

The entrepreneur, on the other hand, will continue with the business in the second period as long as,

$$
V_{j}\left(1-\alpha_{j}\right) E\left[p_{2} \mid j\right]+u_{E}>u_{F} \quad \text { where } j \in\{S, F\}
$$


The entrepreneur will want to continue if the expected value from continuing is greater than the utility after failure, because the utility after failure is the outside option of the entrepreneur if she does not continue. The maximum fraction the entrepreneur will give up in the second period after success in the first period is

$$
\overline{\alpha_{2 S}}=1-\frac{u_{F}-u_{E}}{V_{S} E\left[p_{2} \mid S\right]}
$$

Given both the minimum fraction the investor will accept, $\underline{\alpha_{2 S}}$, as well as the maximum fraction the entrepreneur will give up, $\overline{\alpha_{2 S}}$, an agreement may not be reached. An investor and entrepreneur are able to reach an agreement in the second period as long as

$$
1 \geq \underline{\alpha_{2 S}} \leq \overline{\alpha_{2 S}} \geq 0 \quad \text { Agreement Conditions, } 2^{\text {nd }} \text { period }
$$

The middle inequality requirement is that there are gains from trade. However, those gains must also occur in a region that is feasible, i.e. the investor requires less than $100 \%$ ownership to be willing to invest, $1 \geq \underline{\alpha_{2 S}}$, and the entrepreneur requires less than $100 \%$ ownership to be willing to continue, $\overline{\alpha_{2 S}} \geq 0$. If not, the entrepreneur, for example, might be willing to give up $110 \%$ of the final payoff and the investor might be willing to invest to get this payoff, but it is clearly not economically feasible. For the same reason, even when there are gains from trade in the reasonable range, the resulting negotiation must yield a fraction such that $0 \leq \alpha_{2 j} \leq 1$ otherwise it is bounded by 0 or 1 .

We could find the maximum fraction the entrepreneur would be willing to give up after failure $\left(\overline{\alpha_{2 F}}\right)$, however, we already determined that the investor would require a share $\left(\underline{\alpha_{2 F}}\right)$ greater than $100 \%$ to invest in the second period, which is not economically viable. So no deal will be done after failure. 
If an agreement cannot be reached even after success then clearly the deal will never be funded. However, even those projects for which an agreement could be reached after success may not be funded in the first period if the probability of success in the first period is too low. The following proposition determines the conditions for a potential agreement to be reached to fund the project in the first period. Given that the investor can forecast the second period dilution these conditions can be written in terms of the final fraction of the business the investor or entrepreneur needs to own in the successful state in order to be willing to start.

PROPOSITION 1: The minimum total fraction the investor must receive is

$$
\underline{\alpha_{S_{N}}}=\frac{p_{1} Y(1+r)+X(1+r)^{2}}{p_{1} V_{S} E\left[p_{2} \mid S\right]}
$$

and the maximum total fraction the entrepreneur is willing to give up is

$$
\overline{\alpha_{S_{N}}}=1-\frac{\left(1+p_{1}\right)\left(u_{O}-u_{E}\right)+\left(1-p_{1}\right)\left(u_{O}-u_{F}\right)}{p_{1} V_{S} E\left[p_{2} \mid S\right]}
$$

where the $N$ subscript represents the fact that no agreement will be reached after failure.

See appendix A.ii for proof. We use the $\mathrm{N}$ subscript because in the next section we consider the situation when reputation concerns or bureaucracy result in an agreement to continue even after first period failure (A subscript for Agreement rather than $\mathrm{N}$ for No-agreement). Then we will compare the deals funded in each case. Given the second period fractions found above, the minimum and maximum total fractions imply minimum and maximum first period fractions (found in the appendix for the interested reader). 


\section{B. Commitment}

With the assumption of incomplete contracts there is potential value to an investor of a reputation as 'entrepreneurial friendly' or 'committed', who might then find it costly to shut down a project in the second period. Or alternatively, there might be value in a bureaucratic institution that has a limited ability to shut down a project once started. In this subsection we examine committed investors with an assumed (reputation) cost of early shutdown of c. Then in section IV we allow investors to choose whether or not to have a committed reputation.

We define a committed investor as follows.

DEFINITION 1: A committed investor has a $c>c^{*}=Y(1+r)-V_{F} E\left[p_{2} \mid F\right]$

That is, the cost of shutdown is greater than the expected loses from the project after failure in the first period.

The following proposition solves for the minimum fraction the committed investor will accept in the second period and the maximum fraction the entrepreneur will give up in the second period. These will be used to determine if a deal can be reached.

PROPOSITION 2: The minimum fraction the committed investor is willing to accept for an investment of $Y$ in the second period after success in the first period is

$$
\underline{\alpha_{2 S}}=\frac{Y(1+r)}{V_{S} E\left[p_{2} \mid S\right]}
$$

However, after failure in the first period the minimum fraction the committed investor is willing to accept is

$$
\underline{\alpha_{2 F}}=\frac{Y(1+r)-c}{V_{F} E\left[p_{2} \mid F\right]\left(1-\alpha_{1}\right)}-\frac{\alpha_{1}}{1-\alpha_{1}}
$$


The maximum fraction the entrepreneur will give up in the second period after success in the first period is

$$
\overline{\alpha_{2 S}}=1-\frac{u_{F}-u_{E}}{V_{S} E\left[p_{2} \mid S\right]}
$$

After failure in the first period the maximum fraction the entrepreneur is willing to give up is

$$
\overline{\alpha_{2 F}}=1-\frac{u_{F}-u_{E}}{V_{F} E\left[p_{2} \mid F\right]\left(1-\alpha_{1}\right)}
$$

The proof is in appendix A.i. Both the investor and the entrepreneur must keep a large enough fraction in the second period to be willing to do a deal rather than choose their outside option. These fractions of course depend on whether or not the first period experiment worked.

After success in the first period the agreement conditions are always met. However, after failure in the first period the agreement conditions may or may not be met depending on the parameters of the investment, the investor and the entrepreneur.

LEMMA 1: An agreement can be reached in the second period after failure in the first iff the investor is committed.

\section{PROOF:}

A second period deal after failure can be reached if $\overline{\alpha_{2 F}}-\underline{\alpha_{2 F}} \geq 0$.

$$
\overline{\alpha_{2 F}}-\underline{\alpha_{2 F}}=1-\frac{u_{F}-u_{E}}{V_{F} E\left[p_{2} \mid F\right]\left(1-\alpha_{1}\right)}-\frac{Y(1+r)-c}{V_{F} E\left[p_{2} \mid F\right]\left(1-\alpha_{1}\right)}-\frac{\alpha_{1}}{1-\alpha_{1}}
$$

$\overline{\alpha_{2 F}}-\underline{\alpha_{2 F}}$ is positive iff $V_{F} E\left[p_{2} \mid F\right]-u_{F}+u_{E}-Y(1+r)+c \geq 0$. However, since the utility of the entrepreneur cannot be transferred to the investor, it must also be the case that $V_{F} E\left[p_{2} \mid F\right]-Y(1+r)+c \geq 0$. But if $V_{F} E\left[p_{2} \mid F\right]-Y(1+r)+c \geq 0$ then $V_{F} E\left[p_{2} \mid F\right]-u_{F}+u_{E}-Y(1+r)+c \geq 0$ because $u_{F}-u_{E}<0$. QED 
This lemma makes it clear that only a 'committed' investor will continue to fund the company after failure because $V_{F} E\left[p_{2} \mid F\right]-Y(1+r)<0 .{ }^{11}$

We have now solved for both the minimum second period fraction the committed investor will accept, $\underline{\alpha_{2 j}}$, as well as the maximum second period fraction the entrepreneur will give up, $\overline{\alpha_{2 j}}$, and the conditions under which a second period deal will be done. If either party yields more than these fractions, then they would be better off accepting their outside, low-risk, opportunity rather than continuing the project in the second period.

Stepping back to the first period, a committed investor will invest and an entrepreneur will start the project with a committed investor only if they expect to end up with a large enough fraction after both first and second period negotiations.

PROPOSITION 3: The minimum total fraction the investor is willing to accept is

$$
\underline{\alpha_{S_{A}}}=\frac{Y(1+r)+X(1+r)^{2}-\left(1-p_{1}\right) V_{F} \alpha_{F} E\left[p_{2} \mid F\right]}{p_{1} V_{S} E\left[p_{2} \mid S\right]},
$$

and the maximum fraction the entrepreneur is willing to give up is

$$
\overline{\alpha_{S_{A}}}=1-\frac{2 \Delta w_{1}-\left(1-p_{1}\right) E\left[p_{2} \mid F\right] V_{F}\left(1-\alpha_{F}\right)}{p_{1} V_{S} E\left[p_{2} \mid S\right]}
$$

where the subscript A signifies that an agreement will be reached after first period failure. And where

$$
\alpha_{F}=\gamma\left[\frac{Y(1+r)-c}{V_{F} E\left[p_{2} \mid F\right]}\right]+(1-\gamma)\left[1-\frac{\Delta u_{F}}{V_{F} E\left[p_{2} \mid F\right]}\right]
$$

The proof is in A.ii, however, these are the relatively intuitive outcomes in each situation because each player must expect to make in the good state an amount that at least equals their expected cost plus their expected loss in the bad state.

\footnotetext{
${ }^{11}$ Furthermore, at $c=Y(1+r)$, the committed investor will continue to fund after failure since $V_{F} E\left[p_{2} \mid F\right]>0$. Thus, there is some c such that the investor is committed.
} 
Given the minimum and maximum fractions, we know the project will be started if

$$
1 \geq \underline{\alpha_{S_{i}}} \leq \overline{\alpha_{S_{i}}} \geq 0 \quad \text { Agreement Conditions, } 1^{\text {st }} \text { period }
$$

either with our without a second period agreement after failure $(i \in[A, N])$.

We have now calculated the minimum and maximum required by investors and entrepreneurs. With these fractions we can determine what kinds of deals will be done by the different types of player.

\section{The Desires of the Entrepreneur and Investor}

It is informative to start by considering only the desires of the entrepreneur. The entrepreneur is deciding whether to start the company or take the safe outside option. We have calculated above the fraction of equity the entrepreneur will give up with and without commitment from the investor, $\overline{\alpha_{S_{A}}}$ and $\overline{\alpha_{S_{N}}}$. Our next simple proposition uses these to determine when an entrepreneur would want a committed or failure tolerant investor. Remember that above we defined a 'failure tolerant' or 'committed' investor as one who would still be willing to invest after failure in the first period, i.e., $V_{F} E\left[p_{2} \mid\right.$ $F]-Y(1+r)+c \geq 0$.

PROPOSITION 4: The entrepreneur is willing to give up a larger fraction of the new venture with a committed investor.

\section{PROOF:}

The entrepreneur is willing to give a larger fraction of the new venture to a failure tolerant investor if

$$
\overline{\alpha_{S_{A}}}-\overline{\alpha_{S_{N}}}=\frac{\left(1-p_{1}\right) \gamma\left[V_{F} E\left[p_{2} \mid F\right]-Y(1+r)+c-\Delta u_{F}\right]}{p_{1} V_{S} E\left[p_{2} \mid S\right]}>0
$$


The investor is only failure tolerant, i.e., willing to invest after failure if $V_{F} E\left[p_{2} \mid F\right]-$ $Y(1+r)+c \geq 0$. Given that $\Delta u_{F}<0$, i.e. the entrepreneur finds early failure painful, $\overline{\alpha_{S_{A}}}-\overline{\alpha_{S_{N}}}$ is positive if the investor is failure tolerant. Furthermore, lemma 1 implies that a deal will always be done after early failure when this is true. QED

$u_{F}$ represents the cost of early failure to the entrepreneur. It is intuitive that if early failure is costly to the entrepreneur then they prefer a failure tolerant investor and are more willing to start a new innovative venture with a failure tolerant investor.

This proposition supports the intuition behind failure tolerance. Greater failure tolerance by the investor increases the willingness of the entrepreneur to choose the risky, innovative path. This idea is correct but as the following proposition shows, there is a force coming from the investor that works against this effect.

PROPOSITION 5: The investor is willing to accept a smaller fraction of the new venture if the investor is uncommitted.

For the proof see Appendix A.iv.

Both proposition 4 and 5 are partial equilibrium results that demonstrate common intuition about the two sides of the innovation problem when we consider them separately. The entrepreneur is more willing to start an innovative project for a given offer from the investor if the project will not be shut down after early failure. In this sense failure tolerance encourages innovation.

At the same time proposition 5 demonstrates that the investor is more willing to fund the project if they retain the option to shut down the project after early failure, i.e. real options have value. But this elucidates the clear tension - the investor is more likely to fund the project if he can kill it but the entrepreneur is more likely to start the project if it wont get killed. 
To understand the interaction we must solve for the general equilibrium considering both the entrepreneur and the investor.

\section{A. Commitment or the Guillotine}

A deal can be done to begin the project if $\alpha_{S_{A}} \leq \overline{\alpha_{S_{A}}}$, assuming an agreement will be reached to continue the project after early failure. Alternatively, a deal can be done to begin the project if $\alpha_{S_{N}} \leq \overline{\alpha_{S_{N}}}$, assuming the project will be shut down after early failure. That is, a deal can get done if the lowest fraction the investor will accept, $\underline{\alpha}_{S_{i}}$ is less than the highest fraction the entrepreneur with give up, $\overline{\alpha_{S_{i}}}$. Therefore, given that a second period agreement after failure will or will not be reached, a project can be started if $\overline{\alpha_{S_{A}}}-\underline{\alpha_{S_{A}}} \geq 0$, i.e., if

$$
p_{1} V_{S} E\left[p_{2} \mid S\right]+\left(1-p_{1}\right) V_{F} E\left[p_{2} \mid F\right]-2\left(u_{O}-u_{E}\right)-Y(1+r)-X(1+r)^{2} \geq 0,
$$

or if $\overline{\alpha_{S_{N}}}-\underline{\alpha_{S_{N}}} \geq 0$, i.e., if

$$
p_{1} V_{S} E\left[p_{2} \mid S\right]-2\left(u_{O}-u_{E}\right)+\left(1-p_{1}\right) \Delta u_{F}-p_{1} Y(1+r)-X(1+r)^{2} \geq 0
$$

We can use the above inequalities to determine what types of projects actually can be started and the effects of failure tolerance and a sharp guillotine.

PROPOSITION 6: For any given project there are four possibilities

1) the project can only be started if the investor is committed,

2) the project can only be started if the investor has a sharp guillotine (is uncommitted),

3) the project can be started with either a committed or uncommitted investor, 
4) the project cannot be started.

The proof is left to Appendix A.v. Proposition 6 demonstrates the potential for a tradeoff between failure tolerance and the launching of a new venture. While the entrepreneur would like a committed investor the commitment comes at a price. For some projects and entrepreneurs that price is so high that they would rather not do the deal. For others they would rather do the deal, but just not with a committed investor. Thus when we include the equilibrium cost of failure tolerance we see that it has the potential to both increase the probability that an entrepreneur chooses the innovative path and decrease it.

Essentially the utility of the entrepreneur can be enhanced by moving some of the payout in the success state to the early failure state. This is accomplished by giving a more failure tolerant VC a larger initial fraction in exchange for the commitment to fund the project in the bad state. If the entrepreneur is willing to pay enough in the good state to the investor to make that trade worth it to the investor then the deal can be done. However, there are deals for which this is true and deals for which this is not true. If the committed investor requires too much in order to be failure tolerant in the bad state, then the deal may be more likely to be done by a $\mathrm{VC}$ with a sharp guillotine.

\section{B. Who Funds Experimentation?}

The question is then - which projects are more likely to be done by a committed or uncommitted investor? We can see that projects with higher payoffs, $V_{S}$ or $V_{F}$, or lower costs, $Y$ and $X$, are more likely to be done, but when considering the difference between a committed and an uncommitted investor we must look at the value of the early experiment.

In our model the first stage is an experiment that provides information about the probability of success in the second stage. In an extreme one might have an experiment that demonstrated nothing, i.e., $V_{S} E\left[p_{2} \mid S\right]=V_{F} E\left[p_{2} \mid F\right]$. That is, whether the first stage 
experiment succeeded or failed the updated expected value in the second stage was the same. Alternatively, the experiment might provide a great deal of information. In this case $V_{S} E\left[p_{2} \mid S\right]$ would be much larger than $V_{F} E\left[p_{2} \mid F\right]$. Thus, $V_{S} E\left[p_{2} \mid S\right]-V_{F} E\left[p_{2} \mid F\right]$ is the amount or quality of the information revealed by the experiment.

We define a project as more experimental if the first stage reveals more information. This definition is logical since $V_{S} E\left[p_{2} \mid S\right]-V_{F} E\left[p_{2} \mid F\right]$ is larger if the experiment revealed more about what might happen in the future. In the one extreme the experiment revealed nothing so $V_{S} E\left[p_{2} \mid S\right]-V_{F} E\left[p_{2} \mid F\right]=0$. At the other extreme the experiment could reveal whether or not the project is worthless $\left(V_{S} E\left[p_{2} \mid S\right]-V_{F} E\left[p_{2} \mid F\right]=V_{S} E\left[p_{2} \mid S\right]\right)$. One special case are martingale beliefs with prior expected probability $p$ for both stage 1 and stage 2 and $E\left[p_{2} \mid j\right]$ follows Bayes Rule. In this case projects with weaker priors would be classified as more experimental.

While this is a logical definition of increased experimentation, increasing $V_{S} E\left[p_{2} \mid S\right]-$ $V_{F} E\left[p_{2} \mid F\right]$ might simultaneously increase or decrease the total expected value of the project. When we look at the effects from greater experimentation we want to make sure that we hold constant any change in expected value. Therefore, we define a project as more experimental in a mean preserving way as follows.

DEFINITION 2: A project is more experimental in a mean preserving way if $V_{S} E\left[p_{2} \mid\right.$ $S]-V_{F} E\left[p_{2} \mid F\right]$ is larger for a given $p_{1}$, and expected payoff, $p_{1} V_{S} E\left[p_{2} \mid S\right]+(1-$ $\left.p_{1}\right) V_{F} E\left[p_{2} \mid F\right]$.

We use this definition because it changes the level of experimentation without simultaneously altering the probability of first stage success or the expected value of the project. Certainly a project may be more experimental if $V_{S} E\left[p_{2} \mid S\right]-V_{F} E\left[p_{2} \mid F\right]$ is larger and the expected value is larger. ${ }^{12}$ However, this kind of difference would create two effects -

\footnotetext{
${ }^{12}$ For example, if $E\left[p_{2} \mid F\right]$ is always zero, then the only way to increase $V_{S} E\left[p_{2} \mid S\right]-V_{F} E\left[p_{2} \mid F\right]$ is to increase
} 
one that came from greater experimentation and one that came from increased expected value. Since we know the effects of increased expected value (everyone is more likely to fund a better project) we use a definition that isolates the effect of information.

Note that the notion of increasing experimentation has a relation to, but is not the same as, increasing risk. For example, we could increase risk while holding the experimentation constant by decreasing both $E\left[p_{2} \mid S\right]$ and $E\left[p_{2} \mid F\right]$ and increasing $V_{S}$ and $V_{F}$. This increase in risk would increase the overall risk of the project but would not impact the importance of the first stage experiment.

With this definition we can establish the following proposition

PROPOSITION 7: A more experimental project is more likely to be funded by an uncommitted investor. A more experimental project can potentially only be funded by an uncommitted investor.

\section{PROOF:}

See Appendix A.vi

Proposition 7 makes it clear that the more valuable the information learned from the experiment the more important it is to be able to act on it. A committed investor cannot act on the information and must fund the project anyway while an uncommitted investor can use the information to terminate the project. Therefore, an increase in failure tolerance decreases an investors willingness to fund projects with greater experimentation.

Figure 3 demonstrates the ideas in propositions 6 and 7. Projects with a given expected payoff after success in the first period (Y-axis) or failure in the first period (X-axis) fall into different regions or groups. We only examine projects above the $45^{\circ}$ line because it is not economically reasonable for the expected value after failure to be greater than the expected 
value after success. In the upper left diagram the small dashed lines that run parallel to
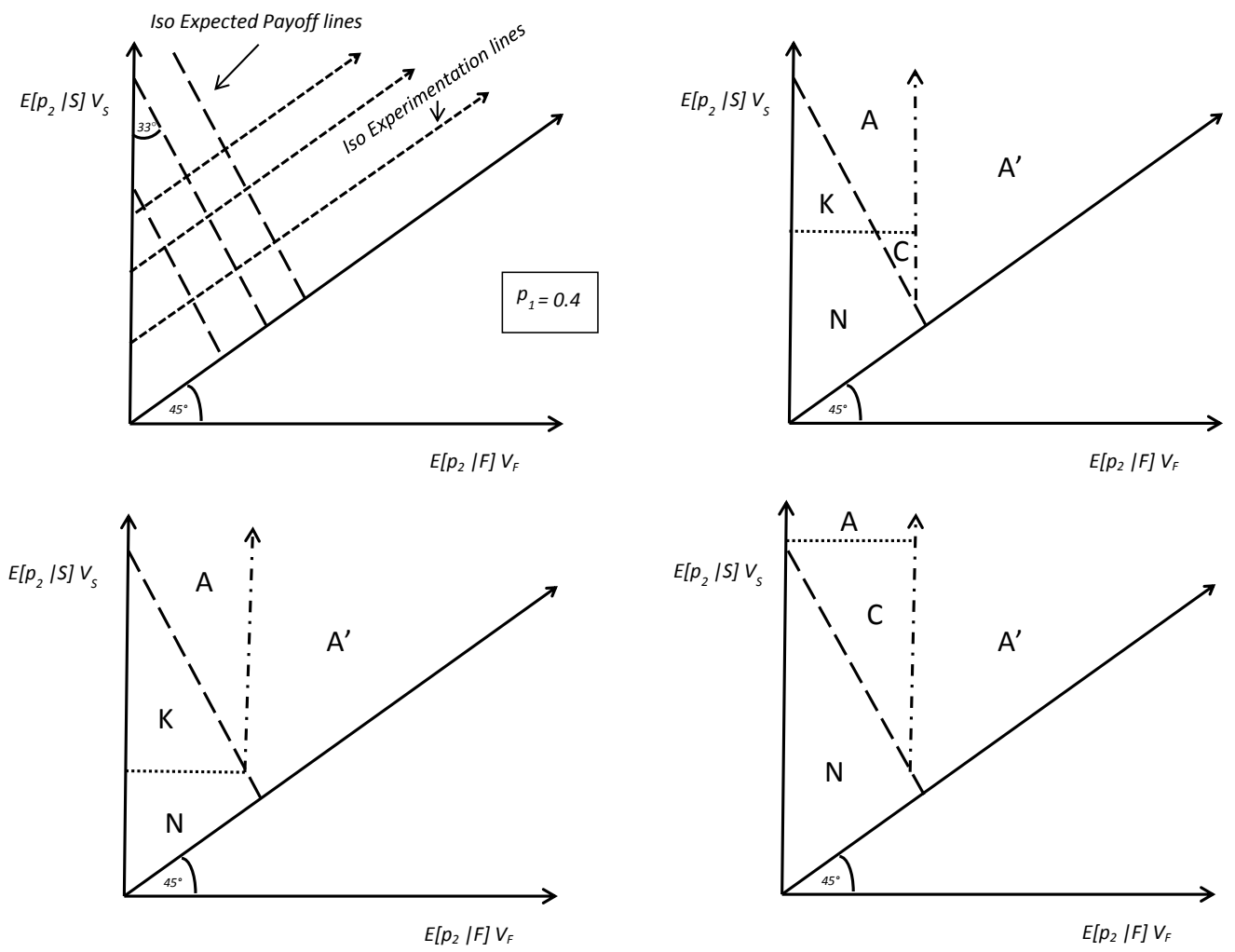

Figure 3. Investor Regions: $\mathrm{N}=$ No Investors, $\mathrm{C}=$ Only Committed Investors, $\mathrm{K}=$ Only Killer Investors, $\mathrm{A}=$ All Investors, A’ = All Invest, Neither Kills

the $45^{\circ}$ line are Iso Experimentation lines, i.e., along these lines $V_{S} E\left[p_{2} \mid S\right]-V_{F} E\left[p_{2} \mid F\right]$ is constant. These projects can be thought of as equally experimental. Moving northeast along an Iso Experimentation line increases the project's value without changing the degree to which it is experimental.

The large dashed lines are Iso Expected Payoff lines. These projects have the same ex ante expected payoff, $p_{1} V_{S} E\left[p_{2} \mid S\right]+\left(1-p_{1}\right) V_{F} E\left[p_{2} \mid F\right]$. They have a negative slope that is defined by the probability of success in the first period $p_{1} \cdot{ }^{13}$ Projects to the northwest

\footnotetext{
${ }^{13}$ In the example shown $p_{1}=0.4$ so the slope of the Iso Expected Payoff Lines is -1.5 resulting in a angle to the Y-axis of approximately 33 degrees.
} 
along an Iso Expected Payoff line are more experimental, but have the same expected value.

The diagram also reinforces that risk is distinct from our notion of experimentation. Each point in the diagram could represent a more or less risky project. A project with a higher $V_{S}$ and $V_{F}$ but lower $E\left[p_{2} \mid S\right]$ and $E\left[p_{2} \mid F\right]$ would be much more risky but could have the same $V_{S} E\left[p_{2} \mid S\right]$ and $V_{F} E\left[p_{2} \mid F\right]$ as an alternative less risky project. Thus, these two different projects would be on the same Iso Experimentation and Iso Expected Payoff line with very different risk.

In the remaining three diagrams in Figure 3 we see the regions discussed in proposition 6. The large dashed line is defined by equation (1). Above this line $\overline{\alpha_{S_{A}}}-\underline{\alpha_{S_{A}}} \geq 0$, so the entrepreneur can reach an agreement with a committed investor. Committed investors will not invest in projects below the large dashed line and can invest in all projects above this line. This line has the same slope as an Iso Expected Payoff Line because with commitment the project generates the full ex ante expected value. However, with an uncommitted, or killer, investor the project is stopped after failure in the first period. Thus, the killer investor's expected payoff is independent of $V_{F} E\left[p_{2} \mid F\right]$. Therefore, uncommitted investors will invest in all projects above the horizontal dotted line. This line is defined by equation (2) because a killer and an entrepreneur can reach an agreement as long as $\overline{\alpha_{S_{N}}}-\alpha_{S_{N}} \geq 0$. The vertical line with both a dot and dash is the line where $V_{F} E\left[p_{2} \mid F\right]=Y(1+r)$. Projects to the right of this line (region A') have a high enough expected value after failure in the first period that no investor would ever kill the project, so we focus our attention to the left of this line. ${ }^{14}$

Where, or whether the dotted and dashed lines cross depends on the other parameters in the problem $\left(c, u_{O}, u_{E}, u_{F}, r, X, Y\right)$ that are held constant in each diagram. If the lines

\footnotetext{
${ }^{14}$ We have assumed throughout the paper that $V_{F} E\left[p_{2} \mid F\right]<Y(1+r)$ to focus on the interesting cases where killing and commitment matter.
} 
cross, as in the upper right diagram, we see five regions. Entrepreneurs with projects with high enough expected values can reach agreements with either type of investor (region A) and those with low enough expected values cannot find investors (region N). However, projects with mid level expected values may only be able to reach an agreement with one of the two types of investors. This displays the intuition of proposition 7 . We see that projects with a given level of expected payoff are more likely to be funded only by a killer (region $\mathrm{K}$ ) if they are more experimental and more likely to be funded only by a committed investor (region C) if they are less experimental.

The following corollary follows directly from proposition 7 and the intuition in the diagrams. If the entrepreneur has a greater dislike of early failure, $u_{F}$ is lower, then the dotted line is higher and the $\mathrm{C}$ region expands and the $\mathrm{K}$ region shrinks. In the lower left and right diagrams in Figure 3 we see it is possible, depending on the magnitude of $u_{F}$ for region $\mathrm{C}$ or $\mathrm{K}$ to disappear. Formally,

COROLLARY 1: Entrepreneurs with a greater dislike of early failure, (smaller $u_{F}$ ), are more likely to have a project such that they can only reach an agreement with a committed investor.

This key result and corollary seem contrary to the notion that failure tolerance increases innovation (Holmstrom (1989), Aghion and Tirole (1994) and Manso (2011)), but actually fits both with this intuition and with the many real world examples. The source of many of the great innovations of our time come both from academia or government labs, places with great failure tolerance but with no criteria for NPV-positive innovation, and from venture capitalist investments, a group that cares a lot about the NPV of their investments, but is often reviled by entrepreneurs for their quickness to shut down a firm. On the other hand, many have argued that large corporations, that also need to worry about the NPV of their 
investments, engage in more incremental innovation and are slow to kill projects. ${ }^{15}$

Our model helps explain this by highlighting that having a strategy of a sharp guillotine allows investors to back the most experimental projects, or those associated with the most radical innovation. Proposition 7 tells us that corporate investors, whose bureaucracy may make them slow to kill projects, will tend to fund projects that are ex ante less experimental (and so wont need to kill them). While VCs, who are generally faster with the financial guillotine, will, on average, fund things with greater learning from early experiments and kill those that don't work out. ${ }^{16}$ Thus, even though corporations will have encouraged more innovation they will only have funded the less experimental projects. And the VCs will have discouraged entrepreneurs from starting projects ex ante. However, ex post they will have funded the most experimental projects and thus will produce the more radical innovations! On the other hand, failure tolerance can induce entrepreneurs to engage in experimentation, but the price of being a failure tolerant investor who cares about NPV may be too high - so that institutions such as academia and the government may also be places that end up financing a lot of radical experimentation, just not in an NPV positive way. ${ }^{17}$

Our model also suggests that employees will likely complain about the stifling environment of the corporation that does not let them innovate (because the corporation won't fund very experimental projects) - leading to spinoffs due to frustration and disagreements about what projects to push forward (see Gompers, Lerner and Scharfstein (2005) and

\footnotetext{
${ }^{15}$ For example, systematic studies of R\&D practices in the U.S. report that large companies tend to focus R\&D on less uncertain, less novel projects more likely to focus on cost reductions or product improvement than new product ideas (e.g. Henderson (1993), Henderson and Clark (1990), Scherer (1991), Scherer (1992), Jewkes, Sawers and Stillerman (1969) and Nelson, Peck and Kalachek (1967)).

${ }^{16}$ Hall and Woodward (2010) report that about 50\% of the venture-capital backed startups in their sample had zero-value exits

${ }^{17}$ Recent work, Chemmanur, Loutskina and Tian (2012), has reported that corporate venture capitalists seem to be more failure tolerant than regular venture capitals. Interestingly, corporate venture capitalists do not seem to have had adequate financial performance but Dushnitsky and Lenox (2006) has shown that corporations benefit in non-pecuniary ways (see theory by Fulghieri and Sevilir (2009)). Our theory suggests that as the need for financial return diminishes, investors can become more failure tolerant and promote innovation.
} 
Klepper and Sleeper (2005)). Corporations that want to retain and fund more radical innovations likely need to become less failure tolerant. ${ }^{18}$ In so doing they will become more willing to fund very experimental projects.

Remember that the notion of increasing experimentation is not the same as increasing risk. Thus, our point is not that more failure tolerant investors, such as corporations, will not do risky projects. Rather they will be less likely to take on projects with a great deal of experimentation and incremental steps where in a great deal of the project value comes from the ability to kill it.

\section{Investors choice of commitment level}

In this section we endogenize the choice by the investor to become committed or not. This allows us to demonstrate the potential for different investing equilibrium environments.

\section{A. The Search for Investments and Investors}

We model the process of the match between investors and entrepreneurs using a simplified version of the classic search model of Diamond-Mortensen-Pissarides (for examples see Diamond (1993) and Mortensen and Pissarides (1994) and for a review see Petrongolo and Pissarides (2001)). ${ }^{19}$ This allows the profits of the investors to vary depending on how many others have chosen to be committed or quick with the guillotine.

We assume that there are a measure of of investors, $M_{I}$, who must choose between having a sharp guillotine, $c=0$, (type $\mathrm{K}$ for 'killer') or committing to fund the next round (type $\mathrm{C}$ for committed). Simultaneously we assume that there are a measure of

\footnotetext{
${ }^{18}$ Interestingly, Seru (2011) reports that mergers reduce innovation. This may be because the larger the corporation the more failure tolerant it becomes and thus endogenously the less willing it becomes to fund innovation.

${ }^{19}$ For a complete development of the model see Pissarides (1990). A search and Nash bargaining combination was recently used by Inderst and Müller (2004) in examining venture investing.
} 
entrepreneurs, $M_{e}$, with one of two types of projects, type A and B. Type A projects occur with probability $\phi$, while the type B projects occur with probability $1-\phi$. As is standard in search models, we define $\theta \equiv M_{I} / M_{e}$. This ratio is important because the relative availability of each type will determine the probability of deal opportunities and therefore influence each firms bargaining ability and choice of what type of investor to become.

Given the availability of investors and entrepreneurs, the number of negotiations to do a deal each period is given by the matching function $\psi\left(M_{I}, M_{e}\right)$. This function is assumed to be increasing in both arguments, concave, and homogenous of degree one. This last assumption ensures that the probability of deal opportunities depends only on the relative scarcity of the investors to entrepreneurs, $\theta$, which in turn means that the overall size of the market does not impact investors or entrepreneurs in a different manner. Each individual investor experiences the same probability of finding an entrepreneur each period, and vice versa. Thus we define the probability that an investor finds an entrepreneur in any period as

$$
\psi\left(M_{I}, M_{e}\right) / M_{I}=\psi\left(1, \frac{M_{e}}{M_{I}}\right) \equiv q_{I}(\theta)
$$

By the properties of the matching function, $q_{I}^{\prime}(\theta) \leq 0$, the elasticity of $q_{I}(\theta)$ is between zero and unity, and $q_{I}$ satisfies standard Inada conditions. Thus, an Investor is more likely to meet an entrepreneur if the ratio of investors to entrepreneurs is low. From an entrepreneurs point of view the probability of finding an investor is $\theta q_{I}(\theta) \equiv q_{e}(\theta)$. This differs from the viewpoint of investors because of the difference in their relative scarcity. $q_{e}^{\prime}(\theta) \geq 0$, thus entrepreneurs are more likely to meet investors if the ratio of investors to entrepreneurs is high.

We assume that the measure of each type of investor and project is unchanging. There- 
fore, the expected profit from searching is the same at any point in time. Formally, this stationarity requires the simultaneous creation of more investors to replace those out of money and more entrepreneurs to replace those who found funding. ${ }^{20}$ We can think of these as new funds, new entrepreneurial ideas or old projects returning for more money. ${ }^{21}$

When an investor and an entrepreneur find each other they must negotiate over any surplus created and settle on an $\alpha_{S}$. The surplus created if the investor is committed is,

$$
\begin{aligned}
& \xi_{C}\left(p_{1}, V_{S}, V_{F}, E\left[p_{2} \mid S\right], E\left[p_{2} \mid F\right], X, Y, r, u_{O}, u_{E}, u_{L}\right) \\
& \quad=p_{1} V_{S} E\left[p_{2} \mid S\right]+\left(1-p_{1}\right) V_{F} E\left[p_{2} \mid F\right]-2\left(u_{O}-u_{E}\right)-Y(1+r)-X(1+r)^{2} .
\end{aligned}
$$

While the surplus created if the investor is not committed is

$$
\begin{aligned}
\xi_{K}\left(p_{1}, V_{S}, V_{F}, E\left[p_{2} \mid S\right], E\left[p_{2} \mid F\right], X, Y, r, u_{O}, u_{E}, u_{L}\right) \\
\quad=p_{1} V_{S} E\left[p_{2} \mid S\right]-2\left(u_{O}-u_{E}\right)+\left(1-p_{1}\right) \Delta u_{F}-p_{1} Y(1+r)-X(1+r)^{2}
\end{aligned}
$$

With an abuse of notation we will refer to the surplus created by investments in type A projects as either $\xi_{C A}$ or $\xi_{K A}$ depending on whether the investor is committed or a killer, and the surplus in type B projects as either $\xi_{C B}$ or $\xi_{K B}$. The difference between type A and B projects is $\xi_{C A}>\xi_{K A}$ while $\xi_{K B}>\xi_{C B}$. That is, type A projects generate more surplus if they receive investment from a committed investor, while type B projects generate more total surplus if they receive investment from a uncommitted investor. ${ }^{22}$

\footnotetext{
${ }^{20}$ Let $m_{j}$ denote the rate of creation of new type $j$ players (investors or entrepreneurs). Stationarity requires the inflows to equal the outflows. Therefore, $m_{j}=q_{j}(\theta) M_{j}$.

${ }^{21}$ In the context of a labor search model, this assumption would be odd, since labor models are focused on the rate of unemployment. There is no analog in venture capital investing, since we are not interested in the 'rate' that deals stay undone.

${ }^{22}$ This assumption is the first that is unusual in the context of search and matching models. Typically these model assume some form of supermodularity (i.e., $\xi_{C A}+\xi_{K B}>\xi_{K A}+\xi_{C B}$ ). However, in our model we allow investors to choose their type so one type should not be assumed to be superior ex-ante.
} 
The set of possible agreements is $\Pi=\left\{\left(\pi_{g f}, \pi_{f g}\right): 0 \leq \pi_{g f} \leq \xi_{g f}\right.$ and $\left.\pi_{f g}=\xi_{g f}-\pi_{g f}\right\}$, where $\pi_{g f}$ is the share of the expected surplus of the project earned by the investor and $\pi_{f g}$ is the share of the expected surplus of the project earned by the entrepreneur, where $g \in[K, C]$ and $f \in[A, B]$.

In equilibrium, if an investor and entrepreneur find each other it is possible to strike a deal as long as the utility from a deal is greater than the outside opportunity for either. If an investor or entrepreneur rejects a deal then they return to searching for another partner which has an expected value of $\pi_{K}, \pi_{C}, \pi_{A}$, or $\pi_{B}$ depending on the player.

This matching model will demonstrate the potential for different venture capital industry outcomes. Although we have reduced the project space down to two projects, this variation is enough to demonstrate the insight.

To determine how firms share the surplus generated by the project we use the Nash bargaining solution, which in this case is just the solution to

$$
\max _{\left(\pi_{g f}, \pi_{f g}\right) \in \Pi}\left(\pi_{g f}-\pi_{g}\right)\left(\pi_{f g}-\pi_{f}\right)
$$

The well known solution to the bargaining problem is presented in the following Lemma. ${ }^{23}$

LEMMA 2: In equilibrium the resulting share of the surplus for an investor of type $g \in$ $[K, C]$ investing in a project of type $f \in[A, B]$ is

$$
\pi_{g f}=\frac{1}{2}\left(\xi_{g f}-\pi_{f}+\pi_{g}\right)
$$

while the resulting share of the surplus for the entrepreneur is $\pi_{f g}=\xi_{g f}-\pi_{g f}$ where the $\pi_{g}, \pi_{f}$ are the disagreement expected values and $\xi_{g f}$ is defined by equations (4) and (5).

${ }^{23}$ The generalized Nash bargaining solution is a simple extension but adds no insight and is omitted. 
Given the above assumptions we can write the expected profits both types of investors and the entrepreneurs, with either type of project, expect to receive if they search for the other.

$$
\pi_{g}=\frac{q_{I}(\theta)\left[\phi \max \left(\pi_{g A}, \pi_{g}\right)+(1-\phi) \max \left(\pi_{g B}, \pi_{g}\right)\right]}{1+r}+\frac{1-q_{I}(\theta)}{1+r} \pi_{g}
$$

If we postulate that $\omega$ fraction of investors choose to be killers, then

$$
\pi_{f}=\frac{q_{e}(\theta)\left[\omega \max \left(\pi_{f K}, \pi_{f}\right)+(1-\omega) \max \left(\pi_{f C}, \pi_{f}\right)\right]}{1+r}+\frac{1-q_{e}(\theta)}{1+r} \pi_{f},
$$

where $g \in[K, C]$ and $f \in[A, B]$. These profit functions are also the disagreement utility of each type during a deal negotiation. With these equations we now have enough to solve the model.

We present the solution to the matching model in the following proposition.

PROPOSITION 8: If search costs are low relative to the value created by joining $B$ projects with a killer $\frac{2 r}{(1-\phi) q_{I}(\theta)+\omega q_{e}(\theta)}<\frac{\xi_{K B}-\xi_{C B}}{\xi_{C B}}$ and A projects with a committed investor $\frac{2 r}{\phi q_{I}(\theta)+(1-\omega) q_{e}(\theta)}<\frac{\xi_{C A}-\xi_{K A}}{\xi_{K A}}$, then at the equilibrium $\omega, 1>\omega *>0$, there is assortative matching and committed investors invest in A type projects and killer investors invest in $B$ type projects. Furthermore, the equilibrium profits of investors who commit $(C)$ or kill (K) are

$$
\begin{aligned}
\pi_{K} & =\frac{(1-\phi) q_{I}(\theta)}{2 r+(1-\phi) q_{I}(\theta)+\omega q_{e}(\theta)} \xi_{K B} \\
\pi_{C} & =\frac{\phi q_{I}(\theta)}{2 r+\phi q_{I}(\theta)+(1-\omega) q_{e}(\theta)} \xi_{C A}
\end{aligned}
$$

And the profits of the entrepreneurs with type $A$ or $B$ projects are

$$
\pi_{A}=\frac{(1-\omega) q_{e}(\theta)}{2 r+\phi q_{I}(\theta)+(1-\omega) q_{e}(\theta)} \xi_{C A}
$$




$$
\pi_{B}=\frac{\omega q_{e}(\theta)}{2 r+(1-\phi) q_{I}(\theta)+\omega q_{e}(\theta)} \xi_{K B}
$$

We leave the proof to the appendix (A.vii). The point of this set up is to have an equilibrium in which the level of competition from other investors determines the profits from being a committed or uncommitted investor. In our simple search and matching model the fraction each investor or entrepreneur gets is endogenously determined by each players ability to find another investor or investment. The result is an intuitive equilibrium in which each player gets a fraction of the total surplus created in a deal, $\xi_{p f}$, that depends on their ability to locate someone else with which to do a deal.

It is interesting to note that even though entrepreneurs would prefer a committed investor, and investors would prefer to be able to kill a project, since commitment is priced in equilibrium, there may be a role for both types of investors.

In order for some investors to choose to be killers while others choose to be committed the expected profits from choosing either type must be the same. If not, investors will switch from one type to the other, raising profits for one type and lowering them for the other, until either there are no investors of one type or until the profits equate. Therefore, the equilibrium $\omega$ is the $\omega=\omega^{*}$ such that the profits from either choice are equivalent.

COROLLARY 2: The equilibrium fraction of investors who choose to be killers is $0 \leq$ $\omega * \leq 1$ where

$$
\omega^{*}=\frac{\left(2 r+\phi q_{I}(\theta)+q_{e}(\theta)\right)(1-\phi) q_{I}(\theta) \xi_{K B}-\left(2 r+(1-\phi) q_{I}(\theta)\right) \phi q_{I}(\theta) \xi_{C A}}{q_{e}(\theta)(1-\phi) q_{I}(\theta) \xi_{K B}+q_{e}(\theta) \phi q_{I}(\theta) \xi_{C A}}
$$

This corollary elucidates the important insight that there are many parameter realization that would result in equilibria in which some investors choose endogenously to be killers while others simultaneously choose to be committed investors. It is not that one choice is superior. Investors are after profits not innovation and thus prices and levels of competition 
adjust so that in many cases it can be equally profitable to be a committed investor who attracts entrepreneurs, but must require a higher fraction of the company, or an uncommitted investor who is less desirable to entrepreneurs but who asks for a smaller fraction of the company. Thus, each type of entrepreneur completes a deal with a different type of investor.

However, it is also interesting to note that there are some equilibria in which no investor chooses to be a killer. The following corollary, points out that whether or not it is profitable to be a killer depends on the level of entrepreneurial aversion to early failure.

COROLLARY 3: The equilibrium fraction of of killer investors, $\omega^{*}$, is a decreasing function of the average entrepreneurial aversion to early failure. Furthermore, for high enough average entrepreneurial aversion to early failure the equilibrium fraction of investors who choose to be killers, $\omega^{*}$, may be zero even though there is a positive measure of projects that create more value with a killer $\left(M_{e}(1-\phi)>0\right)$.

The formal proof left to appendix A.viii but the intuition is as follows. As the fear, or stigma, of early failure increases the surplus created with an uncommitted investor falls. This lowers the profits to being uncommitted so investors exit and become committed investors until the profits from either choice are again equivalent. However, there comes a point where even if an uncommitted investor gets all the surplus from a deal, they would rather be a committed investor even if all other investors are committed (competitive forces are not as bad for profits as no commitment). At this point no investor will choose to be a killer.

Thus, economies with high aversion to early entrepreneurial failure may endogenously contain no investor willing to fund the type of investments that create more surplus with an uncommitted investor. Note that this equilibrium can occur even if there are entrepreneurs 
looking for funding that create more total surplus if funded by a killer. It may be the case, however, that with high general aversion to early failure all investors find it more profitable to form a reputation as committed to attract entrepreneurs and thus look for projects that create more surplus with a committed investor.

The type of project that wont get funded in this economy are those such that $\xi_{K}>\xi_{C}$. This is true if equation (4) > equation (5), or

$$
V_{F} E\left[p_{2} \mid F\right]-Y(1+r)<\Delta u_{F}
$$

As we can see, the projects that wont get funded are those with very low NPV after failure in the first period. These are the projects for which experimentation mattered greatly. Note that it is NOT the high risk projects that do not get funded - the probability of success in the first period $p_{1}$ does not affect the funding condition. Rather, it is those projects that are NPV positive before the experiment but are significantly NPV negative if the early experiment failed. These type of experimental projects cannot receive funding.

This result can help explain the amazing dearth of radical innovations emerging from countries in Europe and Japan. Many believe that the stigma of failure is much higher in these cultures, but it would seem that at least some entrepreneurs would be willing to take the risk. However, what our equilibrium implies is that even those entrepreneurs that are willing to start very experimental projects may find no investor willing to fund that level of experimentation. This is a key insight - the institutional funding environment for innovation is an endogenous equilibrium outcome that may result in places or times with no investors able to fund radical innovation. In equilibrium, all investors choose to be committed investors to attract the large mass of entrepreneurs who are willing to pay for commitment (those with less experimental projects). Thus, when a project arrives 
that needs an investor with a sharp guillotine to fund it (or it is NPV negative) there is no investor able to do it! In this equilibrium, financial intermediaries, such as venture capitalists, can only fund projects that are less experimental.

Anecdotal evidence is consistent with the evidence from this model. For example, much of the 'venture capital' investing outside the US does not go to truly novel radical innovations, but rather to 'me-too' projects and firms that although small, already have customers and products not very different from products sold in many parts of the world, like a chain of eyeglass stores. Martin Varsavsky, one of Europe's leading technology entrepreneurs recently said in an interview with Fortune magazine that "Europeans must accept that success in the tech startup world comes through trial and error. European [investors] prefer great plans that don't fail." ${ }^{24}$ Furthermore, European entrepreneurs, and even those in parts of the United States, complain that they must go to the U.S. or specifically to Silicon Valley to get their ideas funded. In fact Skype, a huge venture backed success, was started by European entrepreneurs Niklas Zennstrm and Janus Friis and based in Luxembourg but received its early funding from US venture capitalists (Bessemer Venture partners and Draper Fisher Jurvetson). Thus, the problem is two-sided; venture capitalists look for less experimental projects to form reputations as failure tolerant because most entrepreneurs want a more failure tolerant backer.

From a social planners or government perspective, the conclusion from this is to both attempt to lower the stigma from early entrepreneurial failure and also to increase the profitability of investing in a set of projects that include some failures. For example, allowing the enhanced use of losses from early stage investments to offset taxes. Potentially every dollar of loss could offset two dollars of gain. This would make it more profitable to be an aggressive investor who actively shut down projects.

\footnotetext{
${ }^{24}$ http://tech.fortune.cnn.com/2012/08/14/europe-vc/
} 


\section{Extensions and Implications}

The tradeoff faced by the investors in our model is one that is more widely applicable. For example, the manifesto of the venture capital firm called 'The Founder's Fund' outlines that they have "never removed a single founder." The intuition from our model would suggest that this would clearly attract entrepreneurs and encourage them to start experimental businesses. However, it should simultaneously change the type of entrepreneur the fund is willing to back. If an investor can't replace the CEO then it would push them to back an entrepreneur who has much more entrepreneurial experience, such as a serial entrepreneur with a proven track record of successes. Such a fund should be less willing to back a young college student with no prior background if they cannot remove him on the chance that he turns out not to be good at running the company.

As another example, consider the Ph.D. programs of Chicago and MIT. Both are excellent programs, but Chicago has a reputation for cutting a large portion of the incoming class after the general exams, while MIT tends to graduate most of the students it admits. Our model does not tell us which produces 'better' professors on average (competition might suggest they were equal on average), but our point is that Chicago's choice should cause them to take more radical or unconventional students, allowing them to enter and

prove themselves in the program, while MIT will tend to admit students who are more conventionally strong. Students who were admitted to both but chose MIT over Chicago likely did so in part because they put a greater cost on the possibility of being cut from the $\mathrm{PhD}$ program after the general exams.

In general our ideas apply to any relationship where in there is the need for exploration, but also the potential to learn from early experiments. In the subsections below, we briefly discuss implications the model has for portfolio decisions of investors as well as 
their decision to spend money to acquire information.

\section{A. Endogenous Fear of Failure}

The idea that the stigma of failure is worse in some parts of the world is generally discussed as a cultural factor. However, Landier (2002) and Gromb and Scharfstein (2002) show how the stigma of failure may be endogenous. In Landier's model, there are multiple equilibria that stem from the following intuition: A low cost of capital encourages entrepreneurs to only continue with the best projects. Thus the pool of 'failed' entrepreneurs has a higher average quality since they are discarding bad projects in the hope of getting better ones, which in turn makes the low cost of capital rational. Gromb and Scharfstein (2002) have a similar combination of labor market and organizational form in their model but with differences in the explicit costs and benefits. In this extension we build on this work and add a similar notion into our model to show it can magnify the likelihood of extreme equilibria with no financiers willing to fund radial experimentation.

We assume that the average aversion to early failure depends on the number of other entrepreneurs that are starting highly experimental projects and being quickly killed. If there are a larger number of entrepreneurs starting and failing then the stigma to having done so decreases. Specifically we assume that $\Delta u_{F}=u_{F}(\omega)-u_{E}$, and $\partial u_{F}(\omega) / \partial \omega>0$. Thus the more investors who choose to be killers, the more surplus is created by an uncommitted investment. The intuitive effects of this extension are discussed below with supporting math in appendix A.ix.

A particularly interesting case could result in which this effect pushed investors toward extremes. As fewer investors chose to be killers, the profits from being a killer investor could in fact fall (even though there would be less competition) because it led entrepreneurs' stigma of failure to rise sufficiently that it outweighed the higher rents available to 
killers from the lower competition for uncommitted investments. Investors would then have even less incentive to be a killer, so even fewer would choose to do so, which would lower profits further. This positive feedback could potentially result in an equilibrium with no killers. However, if a large enough group of investors chose to be killers, then the profits from being a killer could be high enough to sustain an equilibrium with killers. Moreover, if adding even more killer investors caused the profits from being a killer to rise by more than those of committers (who now have less competition) then it could be a Nash equilibrium for all investors to choose to be a killer. When all (or many) investors are killers then the competition for projects is stronger but the surplus created is also larger because the stigma to being killed has fallen. If the increase in surplus is large enough to offset the increase in competition and the profits from being a committed investor are not rising by more than the profits from being a killer then it is profitable for all investors to choose to be a killer.

Thus, what we see in Europe and Japan or even from one city to the next may be an equilibrium in which there are few or no killer investors so the stigma of failure is quite high. Thus, the logic from Landier (2002) extends to the financial side of the market. The financial institutions may be a part of the equilibrium that has little entrepreneurial failure and in fact make it hard for even those few entrepreneurs willing to overcome the stigma because they cannot find funding.

\section{B. Portfolios}

In this subsection we extend the ideas from above to a simple portfolio problem. We examine two specific VCs, one of whom who has chosen to be a killer and the other who is a committed investor. They each have $\$ Z$ to invest. As in a typical venture capital fund, we assume all returns from investing must be returned to the investors so that the VCs 
only have $Z$ to support their projects.

A committed or uncommitted investor who finds an investment must invest $X$, however, they have a different expectations about the need to invest $Y$. The committed investor must invest $Y$ if the first stage experiment fails (because the market will not), and they can choose to invest $Y$ if the first stage succeeds. The uncommitted investor can choose to invest $Y$ if the first stage succeeds and will not invest if the first stage fails. Therefore, a committed investor with $Z$ to invest can expect to make at most $Z /\left(X+\left(1-p_{1}\right) Y\right)$ investments and at least $Z /(X+Y)$ investments. While the uncommitted investor will make at most $Z / X$ investments and expect to make at least $Z /\left(\left(X+p_{1} Y\right)\right.$ investments.

Therefore, we would expect on average for committed investors to take on a smaller number of less experimental projects while the uncommitted investors take on a larger number of more experimental projects. Note that both strategies still expect to be equally profitable. The committed investors own a larger fraction of fewer projects that are more likely to succeed but have to invest more in them. While uncommitted investors own a smaller fraction of more projects and only invest more when it is profitable to do so.

Although the different strategies may be equally profitable there is no question that the committed investor will complete more projects, and the uncommitted investor will have completed more radical projects. Note, however that this assumes that the entrepreneur is willing to receive funding for the more radical innovations from an uncommitted investor. It may be the case that in equilibrium entrepreneurs with very experimental ideas choose to stay as wage earners and all investors choose to fund less experimental projects. Thus, it is not clear ex-ante whether killing or committing will fund more innovation, but conditional on the equilibrium containing both, the killing strategy will fund the more radical experiments. 


\section{Spending on Information}

One could imagine that spending money in an amount greater than $X$ during the first stage of the project might increase the information gathered from the experiment. That is, extra spending might increase $V_{S} E\left[p_{2} \mid S\right]-V_{F} E\left[p_{2} \mid F\right]$. If so, committed investors gain nothing by increasing the information learned from the experiment because they cannot act on it. On the other hand, uncommitted investors gain significantly from increasing $V_{S} E\left[p_{2} \mid S\right]-V_{F} E\left[p_{2} \mid F\right]$ because there is more to bargain over after success in the first period and they don't have to invest after failure. Thus, even if increasing $V_{S} E\left[p_{2} \mid\right.$ $S]-V_{F} E\left[p_{2} \mid F\right]$ simultaneously lowers the probability of success in the first period it is still potentially beneficial to uncommitted investors. This leads to two insights.

First, it implies that a committed investor will spend less on information gathering to determine if the project is a good idea. This may be a negative if spending money to determine whether to go ahead changes a project from negative NPV to positive (see Roberts and Weitzman (1981)). On the other hand, it may be a good thing if the money spent by the uncommitted investor is a waste of resources that does not change whether the project goes forward but just changes the share earned by the investor.

Second, uncommitted investors have an incentive to change the project into one that is more 'all or nothing'. The uncommitted investor must reward the entrepreneur for the expected costs of early termination, but does not pay the ex post costs and thus has an incentive to increase the probability of early failure (and radical success) after the deal is done. This may result in an inefficient amount of early termination risk. Furthermore, one might imagine that entrepreneurs that did not recognize the incentive of the killer VCs to do this might be surprised to find their VC pushing them to take greater early risk. 


\section{Conclusion}

While past work has examined optimal amount of failure tolerance at the individual project level, this idealized planer who adjusts the level of failure tolerance on a projectby-project basis may not occur in many situations. Our contribution is to instead consider the ex ante strategic choice of a firm, investor or government aiming to promote innovation or generate profits. We show that a financial strategy of failure tolerance adopted in the attempt to promote innovation encourages agents to start projects but simultaneously reduces the principals willingness to fund experimental projects. Ultimately an increase in failure tolerance could even reduce total innovation.

We show that in equilibrium, failure tolerance has a price that is increasing with the level of experimentation in the project. This implies two possible sources of market failure. First, projects that cannot pay the price cannot be started in equilibrium and must be funded by the government or else the potential innovation will be lost. These will tend to be radical innovations, since projects that are less experimental can pay the price to get a failure tolerant investor. Second, entrepreneurs' aversion to early failure can affect the equilibrium. Specifically, if a sufficient number of entrepreneurs face a high stigma of early failure, an equilibrium can arise where all investors choose to be failure tolerant and hence only incremental innovations are commercialized in the economy- even if some entrepreneurs are looking for investors to commercialize radical innovations. 


\section{REFERENCES}

Acharya, Viral, and K. Subramanian. 2009. "Bankruptcy Codes and Innovation." Review of Financial Studies, 22: 4949 - 4988.

Aghion, Philippe, and Jean Tirole. 1994. "The Management of Innovation." Quarterly Journal of Economics, 1185-1209.

Aghion, Philippe, John Van Reenen, and Luigi Zingales. 2009. "Innovation and Institutional Ownership." Harvard University working paper.

Akcigit, Ufuk, and Qingmin Liu. 2011. "The Role of information in competitive experimentation." NBER working paper 17602.

Azoulay, Pierre, Joshua S. Graff Zivin, and Gustavo Manso. 2011. "Incentives and Creativity: Evidence from the Academic Life Sciences." RAND Journal of Economics, $42(3): 527-554$.

Battacharya, S., K. Chatterjee, and L. Samuelson. 1986. "Sequential Research and the Adoption of Innovations." Oxford Economic Papers, 38: 219-243.

Bergemann, Dirk, and J. Valimaki. 2006. Bandit Problems. Vol. The New Palgrave Dictionary of Economics, Basingstoke:Macmillan Press.

Bergemann, Dirk, and Ulrich Hege. 2005. "The Financing of Innovation: Learning and Stopping." RAND Journal of Economics, 36: 719-752.

Bergemann, Dirk, Ulrich Hege, and Liang Peng. 2008. "Venture Capital and Sequential Investments." Working Paper.

Burkart, M., D. Gromb, and F. Panunzi. 1997. "Large Shareholders, Monitoring, and the Value of the Firm." Quarterly Journal of Economics, 112: 693 - 728. 
Cerqueiro, Geraldo, Deepak Hegde, Mara Fabiana Penas, and Robert Seamans. 2013. "Personal Bankruptcy Law and Innovation." NYU working paper.

Chemmanur, Thomas J., Elena Loutskina, and Xuan Tian. 2012. "Corporate Venture Capital, Value Creation, and Innovation." Boston College working paper.

Cornelli, Franchesca, and O. Yosha. 2003. "Stage Financing and the Role of Convertible Securities." Review of Economic Studies, 70: 1-32.

Dewatripont, M., and E. Maskin. 1995. "Credit and Efficiency in Centralized and Decentralized Economies." Review of Economic Studies, 62: 541-555.

Diamond, Peter A. 1993. "Search, sticky prices, and inflation." Review of Economic Studies, 60: 53-68.

Dushnitsky, Gary, and Michael J. Lenox. 2006. "When does corporate venture capital investment create firm value?" Journal of Business Venturing, 21: 753-772.

Ewens, Michael, and Christian Fons-Rosen. 2013. "The Consequences of Entrepreneurial Firm Founding on Innovation." CMU working paper.

Ferreira, Daniel, Gustavo Manso, and Andre Silva. 2011. "Incentives to Innovate and The Decision to Go Public or Private." London School of Economics working paper.

Fulghieri, Paolo, and Merih Sevilir. 2009. "Organization and Financing of Innovation, and the Choice between Corporate and Independent Venture Capital." Journal of Financial and Quantitative Analysis, 44: 1291-1321.

Gompers, Paul. 1995. "Optimal Investment, Monitoring, and the Staging of Venture Capital." Journal of Finance, 50: 1461-1489. 
Gompers, Paul, and Josh Lerner. 2004. The Venture Capital Cycle. Cambridge, MA and London:MIT Press.

Gompers, Paul, Josh Lerner, and David Scharfstein. 2005. "Entrepreneurial Spawning: Public Corporations and the Genesis of New Ventures, 1986-1999." Journal of Finance, 60: 577-614.

Gromb, Denis, and David Scharfstein. 2002. "Entrepreneurship in Equilibrium." NBER Working paper number 9001.

Hall, Robert E., and Susan E. Woodward. 2010. "The Burden of the Nondiversifiable Risk of Entrepreneurship." American Economic Review, 100: 1163 - 1194.

Hellmann, Thomas. 1998. "The Allocation of Control Rights in Venture Capital Contracts." RAND Journal of Economics, 29: 57-76.

Hellmann, Thomas, and Manju Puri. 2002. "Venture Capital and the Professionalization of Start-Up Firms: Empirical Evidence." Journal of Finance, 57(1): 169-197.

Hellmann, Thomas, and Veikko Thiele. 2011. "Incentives and Innovation : A Multitasking Approach." American Economic Journal: Microeconomics, 3: 78-128.

Henderson, Rebecca M. 1993. "Underinvestment and Incompetence as Responses to Radical Innovation: Evidence from the Photolithographic Alignment Equipment Industry." The RAND Journal of Economics, 24(2): 248-270.

Henderson, Rebecca M., and Kim B. Clark. 1990. "Architectural Innovation: The Reconfiguration of Existing Product Technologies and the Failure of Established Firms." Administrative Science Quarterly, 35(1): 9-30.

Holmstrom, Bengt. 1989. "Agency Costs and Innovation." Journal of Economic Behavior and Organization, 12: 305-327. 
Inderst, Roman, and Holger M. Müller. 2004. "The effect of capital market characteristics on the value of start-up firms." Journal of Financial Economics, 72: 319-356.

Jensen, R. 1981. "Adoption and Diffusion of an Innovation of Uncertain Probability." Journal of Economic Theory, 27: 182-193.

Jewkes, J., D. Sawers, and R. Stillerman. 1969. The Sources of Invention. London:Macmillan.

Kaplan, Steven, Berk Sensoy, and Per Stromberg. 2009. "Should Investors Bet on the Jockey or the Horse? Evidence from the Evolution of Firms from Early Business Plans to Public Companies." Journal of Finance, 64(1): 75 - 115.

Klepper, Steven, and Sally Sleeper. 2005. "Entry by Spinoffs." Management Science, 51(8): $1291-1306$.

Landier, Augustin. 2002. "Entrepreneurship and the Stigma of Failure." MIT working paper.

Lerner, Josh, and Julie Wulf. 2007. "Innovation and Incentives: Evidence from Corporate R\&D." Review of Economics and Statistics, 89: $634-644$.

Manso, Gustavo. 2011. "Motivating Innovation." Journal of Finance, 66(5): 1823 1860.

Mortensen, Dale T., and Christopher A. Pissarides. 1994. "Job creation and job destruction in the theory of unemployment." Review of Economic Studies, 61: 397-415.

Moscarini, G., and L. Smith. 2001. "The Optimal Level of Experimentation." Econometrica, 69: 1629-1644.

Myers, Stewart. 2000. "Outside Equity." Journal of Finance, 55: 1005 - 1037. 
Nelson, R. R., M. J. Peck, and E. D. Kalachek. 1967. Technology, Economic Growth and Public Policy. Washington:Brookings Institution.

Petrongolo, Barbara, and Christopher A. Pissarides. 2001. "Looking into the black box: A survey of the matching function." Journal of Economic Literature, 38: 390 - 431.

Pissarides, Christopher A. 1990. Equilibrium Unemployment Theory. Cambridge:Basil Blackwell.

Qian, Y., and C. Xu. 1998. "Innovation and Bureaucracy under Soft and Hard Budget Constraints." Review of Economic Studies, 151-164.

Roberts, Kevin, and Martin L. Weitzman. 1981. "Funding Criteria for Research, Development, and Exploration Projects." Economictrica, 49: 12611288.

Sahlman, William A. 1990. "The Structure and Governance of Venture-Capital Organizations." Journal of Financial Economics, 27: 473-521.

Scherer, F. M. 1991. Innovation and Technological Change. New York:Harvester Wheatsheaf.

Scherer, F. M. 1992. "Schumpeter and Plausible Capitalism." Journal of Economic Literature, 30: 1416-1433.

Seru, Amit. 2011. "Firm Boundaries Matter: Evidence from Conglomerates and R\&D Activity." Univeristy of Chicago working paper.

Stein, Jeremy. 1989. "Efficient capital markets, inefficient firms: A model of myopic corporate behavior." Quarterly Journal of Economics, 104: 655669.

Tian, Xuan, and Tracy Yue Wang. 2012. "Tolerance for Failure and Corporate Innovation." Forthcoming Review of Financial Studies. 
Weitzman, Martin L. 1979. "Optimal Search for the Best Alternative.” Economictrica, 47: 641-654. 


\section{A. Appendix}

\section{i. Proof of Proposition 2}

Conditional on a given $\alpha_{1}$ the investor will invest in the second period as long as

$$
V_{j} \alpha_{j} E\left[p_{2} \mid j\right]-Y(1+r)>-c \quad \text { where } j \in\{S, F\}
$$

As noted above, $\mathrm{c}$, is the cost faced by the investor when he stops funding a project and it dies. Thus, the minimum fraction the investor will accept in the second period is

$$
\underline{\alpha_{2 j}}=\frac{Y(1+r)-c}{V_{j} E\left[p_{2} \mid j\right]\left(1-\alpha_{1}\right)}-\frac{\alpha_{1}}{1-\alpha_{1}} .
$$

Thus, an investor will not invest in the second period unless the project is NPV positive accounting for the cost of shutdown. This suggests that an investor who already owned a fraction of the business, $\alpha_{1}$, from the first period would be willing to take a lower minimum fraction in the second period than a new investor, and potentially accept even a negative fraction. However, there is a fraction $\eta$ such that the investor is better off letting an outside investor invest (as long as an outside investor is willing to invest) rather that accept a smaller fraction. If $V_{j} E\left[p_{2} \mid j\right]>Y(1+r)$ (which is true for $j=S$ ) then an outside investor would invest for a fraction greater than or equal to $\frac{Y(1+r)}{V_{S} E\left[p_{2} \mid S\right]}$. The fraction $\eta$ that makes the investor indifferent between investing or not is the $\eta$ such that

$$
\left.\alpha_{1}(1-\eta) V_{S} E\left[p_{2} \mid S\right]\right)=\left(\eta+\alpha_{1}(1-\eta)\right) V_{S} E\left[p_{2} \mid S\right]-Y(1+r)
$$

The left hand side is what the first period investor expects if a new investor purchases $\eta$ in the second period. While the right hand side is the amount the first period investor expects if he purchases $\eta$ in the second period. The $\eta$ that makes this equality hold is $\eta=\frac{Y(1+r)}{V_{S} E\left[p_{2} \mid S\right]}$. Note that $\eta$ does not depend on $c$ because the project continues either way. Thus, after success, an old investor is better off letting a new investor invest than accepting a fraction less than $\frac{Y(1+r)}{V_{S} E\left[p_{2} \mid S\right]} \cdot{ }^{25}$ Thus, the correct minimum fraction that the investor will accept for an investment of $Y$ in the second period after success in the first period is

$$
\underline{\alpha_{2 S}}=\frac{Y(1+r)}{V_{S} E\left[p_{2} \mid S\right]}
$$

However, after failure in the first period then $V_{F} E\left[p_{2} \mid F\right]<Y(1+r)$ and no new investor will invest. Potentially an old (committed) investor would still invest (to avoid paying $c$ ) and the minimum fraction he would accept is

$$
\underline{\alpha_{2 F}}=\frac{Y(1+r)-c}{V_{F} E\left[p_{2} \mid F\right]\left(1-\alpha_{1}\right)}-\frac{\alpha_{1}}{1-\alpha_{1}} .
$$

The entrepreneur, on the other hand, will continue with the business in the second

\footnotetext{
${ }^{25}$ This assumes perfect capital markets that would allow a 'switching' of investors if entrepreneurs tried to extract too much. No results depend on this assumption but it makes the math easier and more intuitive, and we don't want to drive any results off of financial market frictions.
} 
period as long as,

$$
V_{j}\left(1-\alpha_{j}\right) E\left[p_{2} \mid j\right]+u_{E}>u_{F} \quad \text { where } j \in\{S, F\}
$$

Since $\alpha_{j}=\alpha_{2 j}+\alpha_{1}\left(1-\alpha_{2 j}\right)$, for a given $\alpha_{1}$ the maximum fraction the entrepreneur will give to the investor in the second period is

$$
\overline{\alpha_{2 j}}=1-\frac{u_{F}-u_{E}}{V_{j} E\left[p_{2} \mid j\right]\left(1-\alpha_{1}\right)} \quad \forall j \in\{S, F\} .
$$

Similarly to the investor, after success in the first period, there is a point at which the entrepreneur who already owns a fraction $1-\alpha_{1}$ should quit and let the investors hire a new manager rather than take a smaller fraction. Thus, there is a $\eta$ that makes the entrepreneur indifferent between staying and leaving:

$$
\left(1-\alpha_{1}\right) \eta V_{S} E\left[p_{2} \mid S\right]+u_{F}=\left((1-\eta)+\left(1-\alpha_{1}\right) \eta\right) V_{S} E\left[p_{2} \mid S\right]+u_{E}
$$

Thus, the correct maximum fraction the entrepreneur will give up in the second period after success in the first period is ${ }^{26}$

$$
\overline{\alpha_{2 S}}=1-\frac{u_{F}-u_{E}}{V_{S} E\left[p_{2} \mid S\right]}
$$

However, after failure in the first period the maximum that the entrepreneur is willing to give up to keep the business alive is

$$
\overline{\alpha_{2 F}}=1-\frac{u_{F}-u_{E}}{V_{F} E\left[p_{2} \mid F\right]\left(1-\alpha_{1}\right)}
$$

The entrepreneur cannot credibly threaten to leave after failure unless he must give up more than $\overline{\alpha_{2 F}}$, as his departure will just cause the business to be shut down.

\section{ii. $\quad$ Proof of Propositions 1 and 3}

Bargaining will result in a fraction in the second period of $\alpha_{2 j}=\gamma \alpha_{2 j}+(1-\gamma) \overline{\alpha_{2 j}}$. For example, if the entrepreneur has all the bargaining power, $\gamma=1$, then the investor must accept his minimum fraction, $\alpha_{2 j}=\alpha_{2 j}$, while if the investor has all the bargaining power, $\gamma=0$, then the entrepreneur must give up the maximum, $\alpha_{2 j}=\overline{\alpha_{2 j}}$. While if each has some bargaining power then they share the surplus created by the opportunity.

Given this, we can substitute into $\alpha_{j}=\alpha_{2 j}+\alpha_{1}\left(1-\alpha_{2 j}\right)$ and solve for the final fractions the investor and entrepreneur will obtain depending on success or failure at the first stage. Substituting we find $\alpha_{j}=\gamma \alpha_{2 j}+(1-\gamma) \overline{\alpha_{2 j}}+\alpha_{1}\left(1-\left(\gamma \alpha_{2 j}+(1-\gamma) \overline{\alpha_{2 j}}\right)\right)$. This can be rewritten as $\alpha_{j}=\left[\gamma \underline{\alpha_{2 j}}+(1 \overline{-\gamma}) \overline{\alpha_{2 j}}\right]\left(1-\alpha_{1}\right)+\alpha_{1}$. Substituting in for $\underline{\alpha_{2 j}}$ and $\overline{\alpha_{2 j}}$ we find that

$$
\alpha_{S}=\left[\gamma \frac{Y(1+r)}{V_{S} E\left[p_{2} \mid S\right]}+(1-\gamma)\left[1-\frac{u_{F}-u_{E}}{V_{S} E\left[p_{2} \mid S\right]}\right]\right]\left(1-\alpha_{1}\right)+\alpha_{1}
$$

\footnotetext{
${ }^{26}$ This requires the assumption of perfect labor markets that would allow a 'switching' of CEOs among entrepreneurial firms if investors tried to extract too much. No results depend on this assumption but it makes the math easier and more intuitive, and we don't want to drive any results off of labor market frictions.
} 
and $\alpha_{F}$ reduces to

$$
\alpha_{F}=\gamma\left[\frac{Y(1+r)-c}{V_{F} E\left[p_{2} \mid F\right]}\right]+(1-\gamma)\left[1-\frac{u_{F}-u_{E}}{V_{F} E\left[p_{2} \mid F\right]}\right]
$$

Of course, in both cases negotiations must result in a fraction between zero and one. ${ }^{27}$ Note that $\alpha_{F}$ does not depend on the negotiations in the first period because after failure, renegotiation determines the final fractions. ${ }^{28}$ Of course, investors and entrepreneurs will account for this in the first period when they decide whether or not to participate. ${ }^{29} \mathrm{We}$ solve for the first period fractions in appendix A.iii but these are not necessary for the proof.

The solution $\alpha_{F}$ is only correct assuming a deal can be reached between the investor and the entrepreneur in the second period (otherwise the company is shut down after early failure). Interesting outcomes will emerge both when an agreement can and cannot be reached as this will affect both the price of, and the willingness to begin, a project.

Stepping back to the first period, an investor will invest as long as

$$
\begin{aligned}
p_{1}\left[V_{S} \alpha_{S} E\left[p_{2} \mid S\right]-Y(1+r)\right]-X(1+r)^{2} & \\
& +\left(1-p_{1}\right)\left[V_{F} \alpha_{F} E\left[p_{2} \mid F\right]-Y(1+r)\right] \geq 0
\end{aligned}
$$

if the 2 nd period agreement conditions are met after failure. Or,

$$
p_{1}\left[V_{S} \alpha_{S} E\left[p_{2} \mid S\right]-Y(1+r)\right]-X(1+r)^{2}-\left(1-p_{1}\right) c \geq 0
$$

if they are not.

The entrepreneur will choose to innovate and start the project if

$$
\begin{aligned}
& p_{1}\left[V_{S}\left(1-\alpha_{S}\right) E\left[p_{2} \mid S\right]+u_{E}\right]+u_{E} \\
& +\left(1-p_{1}\right)\left[V_{F}\left(1-\alpha_{F}\right) E\left[p_{2} \mid F\right]+u_{E}\right] \geq 2 u_{O}
\end{aligned}
$$

if the 2nd period agreement conditions are met after failure. Or,

$$
p_{1}\left[V_{S}\left(1-\alpha_{S}\right) E\left[p_{2} \mid S\right]+u_{E}\right]+u_{E}+\left(1-p_{1}\right) u_{F} \geq 2 u_{O}
$$

if they are not.

The four above equations can be used to solve for the minimum fractions needed by the investor and entrepreneur both when a deal after failure can be reached and when it cannot. If the agreement conditions in the 2 nd period after failure are met, then the minimum fraction the investor is willing to receive in the successful state and still choose to invest in the project is found by solving equation (A-3) for the minimum $\alpha_{S}$ such that

\footnotetext{
${ }^{27}$ Since negotiations must result in a fraction between zero and one, then if a deal can be done then if $\gamma<$ $\left(u_{F}-u_{E}\right) /\left(Y(1+r)-c-V_{F} E\left[p_{2} \mid F\right]+u_{F}-u_{E}\right)$ then $\alpha_{F}=1$, or if $\gamma<-\left(u_{F}-u_{E}\right) /\left(Y(1+r)-V_{S} E\left[p_{2} \mid S\right]+u_{F}-u_{E}\right)$ then $\alpha_{S}=1$. Since $c \leq Y(1+r)$ the negotiations will never result in a fraction less than zero.

${ }^{28}$ In actual venture capital deals so called 'down rounds' that occur after poor outcomes often result in a complete rearrangement of ownership fractions between the first round, second round and entrepreneur.

${ }^{29}$ Alternatively we could assume that investors and entrepreneurs predetermine a split for for every first stage outcome. This would require complete contracts and verifiable states so seems less realistic but would not change the intuition or implications of our results.
} 
the inequality holds:

$$
\underline{\alpha_{S_{A}}}=\frac{Y(1+r)+X(1+r)^{2}-\left(1-p_{1}\right) V_{F} \alpha_{F} E\left[p_{2} \mid F\right]}{p_{1} V_{S} E\left[p_{2} \mid S\right]}
$$

where the subscript A signifies that an agreement can be reached after first period failure.

The maximum fraction the entrepreneur can give up in the successful state and still be willing to choose the entrepreneurial project is found by solving equation (A-5) for the maximum $\alpha_{S}$ such that the inequality holds:

$$
\overline{\alpha_{S_{A}}}=1-\frac{2\left(u_{O}-u_{E}\right)-\left(1-p_{1}\right) E\left[p_{2} \mid F\right] V_{F}\left(1-\alpha_{F}\right)}{p_{1} V_{S} E\left[p_{2} \mid S\right]}
$$

where $\alpha_{F}$ is defined in equation (A-2) in both $\overline{\alpha_{S_{A}}}$ and $\alpha_{S_{A}}$. Both $\overline{\alpha_{S_{A}}}$ and $\alpha_{S_{A}}$ depend on the negotiations in the failed state, $\alpha_{F}$, because the minimum share the players need to receive in the the good state to make them willing to choose the project depends on how badly they do in the bad state.

If a second period agreement after failure cannot be reached then the minimum fraction of the investor and the maximum fraction of the entrepreneur are found by solving equations (A-4) and (A-6) respectively, to find

$$
\underline{\alpha_{S_{N}}}=\frac{p_{1} Y(1+r)+X(1+r)^{2}}{p_{1} V_{S} E\left[p_{2} \mid S\right]}
$$

and

$$
\overline{\alpha_{S_{N}}}=1-\frac{\left(1+p_{1}\right)\left(u_{O}-u_{E}\right)+\left(1-p_{1}\right)\left(u_{O}-u_{F}\right)}{p_{1} V_{S} E\left[p_{2} \mid S\right]}
$$

where the $\mathrm{N}$ subscript represents the fact that no agreement can be reached after failure.

\section{iii. Derivation of first period fractions}

The maximum and minimum required shares after first period success, $\overline{\alpha_{S_{i}}}$ and $\alpha_{S_{i}}$, directly imply first period minimum an maximum fractions, $\overline{\alpha_{1_{i}}}$ and $\underline{\alpha_{1_{i}}}(i \in[A, \overline{N]})$, because we already know from above, equation (A-1), that

$$
\alpha_{S}=\left[\gamma \frac{Y(1+r)}{V_{S} E\left[p_{2} \mid S\right]}+(1-\gamma)\left(1-\frac{u_{F}-u_{E}}{V_{S} E\left[p_{2} \mid S\right]}\right)\right]\left(1-\alpha_{1}\right)+\alpha_{1}
$$

Thus, we can solve for the $\alpha_{1}$ that just gives the investor his minimum $\alpha_{S}$. Let $\mathrm{Z}$ equal the term in brackets in the equation above and we can solve for $\alpha_{1}$ as a function of $\alpha_{S}$.

$$
\alpha_{1}=\frac{\alpha_{S}-Z}{1-Z}
$$

Plugging in $\underline{\alpha_{S_{A}}}$ for $\alpha_{S}$ yields the minimum required investor fraction $\underline{\alpha_{1_{A}}}$ :

$$
\underline{\alpha_{1_{A}}}=\frac{\frac{Y(1+r)+X(1+r)^{2}-\left(1-p_{1}\right) V_{F} \alpha_{F} E\left[p_{2} \mid F\right]}{p_{1} V_{S} E\left[p_{2} \mid S\right]}-Z}{1-Z}
$$


as a function of $\alpha_{F}$. And substituting in for $\alpha_{F}$ from equation (A-2) and Z from above yields,

$$
\begin{aligned}
\underline{\alpha_{1_{A}}}=1-\frac{p_{1} V_{S} E\left[p_{2} \mid S\right]-p_{1} Y}{}(1+r)-X(1+r)^{2}-\left(1-p_{1}\right) \gamma c \\
p_{1}\left(\gamma V_{S} E\left[p_{2} \mid S\right]-\gamma Y(1+r)+(1-\gamma)\left(u_{F}-u_{E}\right)\right) \\
-\frac{\left(1-p_{1}\right)(1-\gamma)\left(V_{F} E\left[p_{2} \mid F\right]-Y(1+r)-\left(u_{F}-u_{E}\right)\right)}{p_{1}\left(\gamma V_{S} E\left[p_{2} \mid S\right]-\gamma Y(1+r)+(1-\gamma)\left(u_{F}-u_{E}\right)\right)}
\end{aligned}
$$

This is the minimum fraction required by the investor assuming that a deal can be achieved in the second period after failure in the first period. ${ }^{30}$ In equilibrium the investor's minimum depends on the entrepreneur's gains and costs because they must negotiate and participate.

If instead, an agreement cannot be reached after failure in the first period then the project is stopped. In this case the minimum fraction required by the investor can be found by plugging $\alpha_{S_{N}}$ into equation (A-7) for $\alpha_{S}$, where $\alpha_{S_{N}}$ is the minimum when no second period deal $\overline{c a n}$ be reached. In this case the minimum required investor fraction $\alpha_{1_{N}}$ is

$$
\underline{\alpha_{1_{N}}}=\frac{\frac{p_{1} Y(1+r)+X(1+r)^{2}}{p_{1} V_{S} E\left[p_{2} \mid S\right]}-Z}{1-Z}
$$

or,

$$
\underline{\alpha_{1_{N}}}=1-\frac{p_{1} V_{S} E\left[p_{2} \mid S\right]-p_{1} Y(1+r)-X(1+r)^{2}}{p_{1}\left(\gamma V_{S} E\left[p_{2} \mid S\right]-\gamma Y(1+r)+(1-\gamma)\left(u_{F}-u_{E}\right)\right)}
$$

We can similarly calculate the maximum fraction the entrepreneur is willing to give up in the first period. The maximum fraction can be found by plugging $\overline{\alpha_{S_{i}}}$ into equation (A7) for $\alpha_{S_{i}}$, where $\overline{\alpha_{S_{i}}}(i \in[A, N])$ is the maximum when either a second period agreement after failure can $(\mathrm{A})$ or cannot $(\mathrm{N})$ be reached. When a second period agreement can be reached $\overline{\alpha_{1}}$ is

$$
\overline{\alpha_{1_{A}}}=1-\frac{2\left(u_{O}-u_{E}\right)-\left(1-p_{1}\right) E\left[p_{2} \mid F\right] V_{F}\left(1-\alpha_{F}\right)}{p_{1}\left(\gamma V_{S} E\left[p_{2} \mid S\right]-\gamma Y(1+r)+(1-\gamma)\left(u_{F}-u_{E}\right)\right)}
$$

And when a second period deal after failure cannot be reached $\overline{\alpha_{1_{N}}}$ is

$$
\overline{\alpha_{1_{N}}}=1-\frac{\left(1+p_{1}\right)\left(u_{O}-u_{E}\right)+\left(1-p_{1}\right)\left(u_{O}-u_{F}\right)}{p_{1}\left(\gamma V_{S} E\left[p_{2} \mid S\right]-\gamma Y(1+r)+(1-\gamma)\left(u_{F}-u_{E}\right)\right)}
$$

\footnotetext{
${ }^{30}$ Technical note: with extreme values it is possible that $\alpha_{F}$ would be greater than 1 or less than zero. In these cases $\alpha_{F}$ is bound by either zero or 1 . This would cause the $\alpha_{1}$ to increase or decrease. This dampens some of the effects in extreme cases but alters no results. To simplify the exposition we assume that parameters are in the reasonable range such that the investor and entrepreneur would not be willing to agree to a share greater than 1 or less than zero.
} 


\section{iv. Proof of Proposition 5:}

For a moment assume that the uncommitted investor has an explicit cost of early termination of $\mathrm{c}$ (where $\mathrm{c}$ is zero). In which case

$$
\underline{\alpha_{S_{A}}}-\underline{\alpha_{S_{N}}}=\frac{\left(1-p_{1}\right)\left(Y(1+r)-V_{F} \alpha_{F} E\left[p_{2} \mid F\right]-c\right)}{p_{1} V_{S} E\left[p_{2} \mid S\right]}>0
$$

for any $0 \leq \alpha_{F} \leq 1$. If we increase $\mathrm{c}$ to $\hat{c}$ to make the investor failure tolerant, then just at the point where $V_{F} E\left[p_{2} \mid F\right]-Y(1+r)+\hat{c}=0$ it is still the case that $\alpha_{S_{A}} \geq \alpha_{S_{N}}$, because $\alpha_{F} \leq 1$. Therefore, since $\partial \alpha_{S_{N}} / \partial c>0, \alpha_{S_{N}}(\hat{c})>\alpha_{S_{N}}(c)$. Therefore, $\overline{\text { since }}$ $\partial \alpha_{S_{A}} / \partial c>0 \forall c$ we know that $\alpha_{S_{A}}(\overline{c \geq \hat{c}})>\alpha_{S_{N}}(\hat{c})>\alpha_{S_{N}}(c)$. Thus, the minimum a committed investor is willing to accept is always greater than the minimum of an investor who is uncommitted i.e., $\alpha_{S_{A}}(c \geq \hat{c})>\alpha_{S_{N}}(c)$. And equation (A-7) demonstrates that a smaller $\alpha_{S_{i}}$ results in a smaller $\alpha_{1}$. Furthermore, Lemma 1 implies that an uncommitted investor cannot do a deal after early failure. QED

\section{v. Proof of Proposition 6:}

It is clearly possible that both $\overline{\alpha_{S_{A}}}-\alpha_{S_{A}}<0$ and $\overline{\alpha_{S_{N}}}-\alpha_{S_{N}}<0$. For example, a project with a low enough $V_{S}$ and/or $V_{F}$ (or high X) could have both differences less than zero for any positive c (i.e., independent of the failure tolerance of the investor). Similarly, for a high enough $V_{S}$ and/or $V_{F}$ (or low $\mathrm{X}$ ) both $\overline{\alpha_{S_{A}}}-\alpha_{S_{A}}>0$ and $\overline{\alpha_{S_{N}}}-\alpha_{S_{N}}>0$, even for c equal to the maximum c of $Y(1+r)$. Thus, extremely bad projects will not be started and extremely good projects will be started by any type of investor.

Committed investors, who will reach an agreement after early failure, will start the project if $\overline{\alpha_{S_{A}}}-\alpha_{S_{A}} \geq 0$. Uncommitted investors, who will kill the project after early failure, will start the project if $\overline{\alpha_{S_{N}}}-\underline{\alpha_{S_{N}}} \geq 0$. The difference between $\overline{\alpha_{S_{A}}}-\underline{\alpha_{S_{A}}}$ and $\overline{\alpha_{S_{N}}}-\alpha_{S_{N}}$ is

$$
\frac{\left(1-p_{1}\right) V_{F} E\left[p_{2} \mid F\right]-\left(1-p_{1}\right) \Delta u_{F}-\left(1-p_{1}\right) Y(1+r)}{p_{1} V_{S} E\left[p_{2} \mid S\right]}
$$

For an uncommitted investor, equation (A-8) may be positive or negative depending on the relative magnitudes of $V_{F} E\left[p_{2} \mid F\right], \Delta u_{F}$, and $Y(1+r)$. If it is positive, then for some parameters $\overline{\alpha_{S_{A}}}-\alpha_{S_{A}} \geq 0$ while $\overline{\alpha_{S_{N}}}-\alpha_{S_{N}}<0$. In these cases the project can only be funded by a committed investor. If the difference in equation (A-8) is negative then for some parameters $\overline{\alpha_{S_{A}}}-\alpha_{S_{A}}<0$ while $\overline{\alpha_{S_{N}}}-\alpha_{S_{N}} \geq 0$. In these cases the project can only be funded by an uncommitted investor. QED

\section{vi. Proof of Proposition \%:}

A project can be funded by a committed investor if $\overline{\alpha_{S_{A}}}-\alpha_{S_{A}} \geq 0$. For two projects with the same expected payout, $\overline{\alpha_{S_{A}}}-\alpha_{S_{A}}$ has the same sign, i.e., both projects either can or cannot be funded and changing $\overline{V_{S} E}\left[p_{2} \mid S\right]-V_{F} E\left[p_{2} \mid F\right]$ does not change that. This can be seen by noting that the numerator of equation (1) is unaffected by changes in $V_{S} E\left[p_{2} \mid S\right]-V_{F} E\left[p_{2} \mid F\right]$ as long as $p_{1} V_{S} E\left[p_{2} \mid S\right]+\left(1-p_{1}\right) V_{F} E\left[p_{2} \mid F\right]$ does not change. 
A project can be funded by an uncommitted investor if $\overline{\alpha_{S_{N}}}-\alpha_{S_{N}} \geq 0$. If $V_{S} E\left[p_{2} \mid S\right]-$ $V_{F} E\left[p_{2} \mid F\right]$ increases but $p_{1}$, and the expected payout, $p_{1} V_{S} E\left[p_{2} \overline{\mid S]}+\left(1-p_{1}\right) V_{F} E\left[p_{2} \mid F\right]\right.$, stay the same, then $V_{S} E\left[p_{2} \mid S\right]$ must have increased and $V_{F} E\left[p_{2} \mid F\right]$ must have decreased. In which case $\overline{\alpha_{S_{N}}}-\underline{\alpha_{S_{N}}}$ increased (see equation (2)) and the difference between $\overline{\alpha_{S_{A}}}-\underline{\alpha_{S_{A}}}$ and $\overline{\alpha_{S_{N}}}-\alpha_{S_{N}}$ (equation $(\mathrm{A}-8)$ ) decreased. Therefore, there are a larger set of parameters such that $\overline{\alpha_{S_{A}}}-\alpha_{S_{A}}<0$ while $\overline{\alpha_{S_{N}}}-\underline{\alpha_{S_{N}}} \geq 0$, i.e., the project can only be funded by an uncommitted investor. QED

\section{vii. Proof of Proposition 8:}

Let $g \in[K, C]$ represent the investor type investing in a project of type $f \in[A, B]$, and let $\omega$ represent the fraction of investors that choose to be killers $(\mathrm{K})$ rather than committed (C). Also, let $\pi_{g}$ and $\pi_{f}$ represent the expected profits of the investor and entrepreneur respectively before they find a partner, while $\pi_{g f}$ and $\pi_{f g}$ represent their respective expected profits conditional on doing a deal with a partner of type $f$ or $g$ respectively.

We begin with equation (8) and assume that $\pi_{C}<\pi_{C A}, \pi_{C}>\pi_{C B}, \pi_{K}<\pi_{K B}$, $\pi_{K}>\pi_{K A}$, which we later verify in equilibrium. Thus,

$$
\begin{gathered}
\pi_{K}=\frac{q_{I}(\theta)\left[\phi \pi_{K}+(1-\phi) \pi_{K B}\right]}{1+r}+\frac{1-q_{I}(\theta)}{1+r} \pi_{K} \\
\pi_{C}=\frac{q_{I}(\theta)\left[\phi \pi_{C A}+(1-\phi) \pi_{C}\right]}{1+r}+\frac{1-q_{I}(\theta)}{1+r} \pi_{C}
\end{gathered}
$$

Next we use equation (9) and assume that $\pi_{A}<\pi_{A C}, \pi_{A}>\pi_{B C}, \pi_{B}<\pi_{B K}, \pi_{B}>\pi_{B C}$, which we also verify in equilibrium.

$$
\begin{aligned}
& \pi_{A}=\frac{q_{e}(\theta)\left[\omega \pi_{A}+(1-\omega) \pi_{A C}\right]}{1+r}+\frac{1-q_{e}(\theta)}{1+r} \pi_{A} \\
& \pi_{B}=\frac{q_{e}(\theta)\left[\omega \pi_{B K}+(1-\omega) \pi_{B}\right]}{1+r}+\frac{1-q_{e}(\theta)}{1+r} \pi_{B}
\end{aligned}
$$

Using Lemma 2 and solving we find

$$
\begin{gathered}
\pi_{K}=\frac{(1-\phi) q_{I}(\theta)}{2 r+(1-\phi) q_{I}(\theta)}\left[\xi_{K B}-\pi_{B}\right] \\
\pi_{C}=\frac{\phi q_{I}(\theta)}{2 r+\phi q_{I}(\theta)}\left[\xi_{C A}-\pi_{A}\right] \\
\pi_{A}=\frac{(1-\omega) q_{e}(\theta)}{2 r+(1-\omega) q_{e}(\theta)}\left[\xi_{C A}-\pi_{C}\right] \\
\pi_{B}=\frac{\omega q_{e}(\theta)}{2 r+\omega q_{e}(\theta)}\left[\xi_{K B}-\pi_{K}\right]
\end{gathered}
$$

Therefore, with 4 equations and 4 unknowns we can solve for $\pi_{K}, \pi_{C}, \pi_{A}$, and $\pi_{B}$.

$$
\pi_{K}=\frac{(1-\phi) q_{I}(\theta)}{2 r+(1-\phi) q_{I}(\theta)+\omega q_{e}(\theta)} \xi_{K B}
$$




$$
\begin{aligned}
& \pi_{C}=\frac{\phi q_{I}(\theta)}{2 r+\phi q_{I}(\theta)+(1-\omega) q_{e}(\theta)} \xi_{C A} \\
& \pi_{A}=\frac{(1-\omega) q_{e}(\theta)}{2 r+\phi q_{I}(\theta)+(1-\omega) q_{e}(\theta)} \xi_{C A} \\
& \pi_{B}=\frac{\omega q_{e}(\theta)}{2 r+(1-\phi) q_{I}(\theta)+\omega q_{e}(\theta)} \xi_{K B}
\end{aligned}
$$

These are the equilibrium profits, but we must confirm that $\pi_{C B}<\pi_{C}<\pi_{C A}$ and $\pi_{K A}<\pi_{K}<\pi_{K B}$ as well as $\pi_{A K}<\pi_{A}<\pi_{A C}$ and $\pi_{B C}<\pi_{B}<\pi_{B K}$.

Lemma 2 tells us that $\pi_{g f}=\frac{1}{2}\left(\xi_{g f}-\pi_{f}+\pi_{g}\right)$ and $\pi_{f g}=\xi_{g f}-\pi_{g f}$. Thus checking all the inequalities just above reduces to checking that $\xi_{C B}-\pi_{B}<\pi_{C}<\xi_{C A}-\pi_{A}$ and that $\xi_{K A}-\pi_{A}<\pi_{K}<\xi_{K B}-\pi_{B}$. Substituting for $\pi_{K}, \pi_{C}, \pi_{A}$, and $\pi_{B}$ from above we see that it is always the case that $\pi_{C}<\xi_{C A}-\pi_{A}$ and $\pi_{K}<\xi_{K B}-\pi_{B}$ as long as $\xi_{K B}$ and $\xi_{C A}$ are positive (i.e. a deal creates value). Furthermore, since at the equilibrium $\omega=\omega^{*}$ it must be the cast that $\pi_{C}=\pi_{K}$, therefore, $\xi_{C B}-\pi_{B}<\pi_{C}$ as long as

$$
\frac{2 r}{(1-\phi) q_{I}(\theta)+\omega q_{e}(\theta)}<\frac{\xi_{K B}-\xi_{C B}}{\xi_{C B}}
$$

and $\xi_{K A}-\pi_{A}<\pi_{K}$ as long as

$$
\frac{2 r}{\phi q_{I}(\theta)+(1-\omega) q_{e}(\theta)}<\frac{\xi_{C A}-\xi_{K A}}{\xi_{K A}}
$$

viii. Proof of Corollary 3:

Since $\partial \pi_{K} / \partial \omega<0$ and $\partial \pi_{C} / \partial \omega>0$, single crossing is insured and $\omega^{*}$ is determined the point at which $\pi_{K}=\pi_{C}$ using the results from proposition 8. As corollary 2 notes this results in

$$
\omega^{*}=\frac{\left(2 r+\phi q_{I}(\theta)+q_{e}(\theta)\right)(1-\phi) q_{I}(\theta) \xi_{K B}-\left(2 r+(1-\phi) q_{I}(\theta)\right) \phi q_{I}(\theta) \xi_{C A}}{q_{e}(\theta)(1-\phi) q_{I}(\theta) \xi_{K B}+q_{e}(\theta) \phi q_{I}(\theta) \xi_{C A}}
$$

Or, $\omega^{*}=1$ if $\pi_{K}(1)>\pi_{C}(1)$ or $\omega^{*}=0$ if $\pi_{K}(0)>\pi_{C}(0)$.

As the fear or stigma of early failure decreases, $\Delta u_{F}$ increases. Using equations (4) and (5) we find that $\frac{\partial \xi_{C f}}{\partial \Delta u_{F}}=0$ and $\frac{\partial \xi_{K f}}{\partial \Delta u_{F}}=\left(1-p_{1}\right)>0$. Therefor,

$$
\begin{array}{r}
\frac{\partial \omega^{*}}{\partial \Delta u_{F}}=\frac{\left(q_{e}(\theta)(1-\phi) q_{I}(\theta) \xi_{K B}\right)\left(2 r+\phi q_{I}(\theta)+q_{e}(\theta)\right)(1-\phi) q_{I}(\theta) \frac{\partial \xi_{K B}}{\partial \Delta u_{F}}}{\left(q_{e}(\theta)(1-\phi) q_{I}(\theta) \xi_{K B}+q_{e}(\theta) \phi q_{I}(\theta) \xi_{C A}\right)^{2}} \\
+\frac{\left(q_{e}(\theta) \phi q_{I}(\theta) \xi_{C A}\right)\left(2 r+\phi q_{I}(\theta)+q_{e}(\theta)\right)(1-\phi) q_{I}(\theta) \frac{\partial \xi_{K B}}{\partial \Delta u_{F}}}{\left(q_{e}(\theta)(1-\phi) q_{I}(\theta) \xi_{K B}+q_{e}(\theta) \phi q_{I}(\theta) \xi_{C A}\right)^{2}} \\
-\frac{\left[\left(2 r+\phi q_{I}(\theta)+q_{e}(\theta)\right)(1-\phi) q_{I}(\theta) \xi_{K B}\right] q_{e}(\theta)(1-\phi) q_{I}(\theta) \frac{\partial \xi_{K B}}{\partial \Delta u_{F}}}{\left(q_{e}(\theta)(1-\phi) q_{I}(\theta) \xi_{K B}+q_{e}(\theta) \phi q_{I}(\theta) \xi_{C A}\right)^{2}} \\
+\frac{\left[\left(2 r+(1-\phi) q_{I}(\theta)\right) \phi q_{I}(\theta) \xi_{C A}\right] q_{e}(\theta)(1-\phi) q_{I}(\theta) \frac{\partial \xi_{K B}}{\partial \Delta u_{F}}}{\left(q_{e}(\theta)(1-\phi) q_{I}(\theta) \xi_{K B}+q_{e}(\theta) \phi q_{I}(\theta) \xi_{C A}\right)^{2}}
\end{array}
$$


And since the first and third terms are the same but with opposite sign this reduces to

$$
\begin{array}{r}
\frac{\partial \omega^{*}}{\partial \Delta u_{F}}=\frac{\left(q_{e}(\theta) \phi q_{I}(\theta) \xi_{C A}\right)\left(2 r+\phi q_{I}(\theta)+q_{e}(\theta)\right)(1-\phi) q_{I}(\theta) \frac{\partial \xi_{K B}}{\partial \Delta u_{F}}}{\left(q_{e}(\theta)(1-\phi) q_{I}(\theta) \xi_{K B}+q_{e}(\theta) \phi q_{I}(\theta) \xi_{C A}\right)^{2}} \\
+\frac{\left[\left(2 r+(1-\phi) q_{I}(\theta)\right) \phi q_{I}(\theta) \xi_{C A}\right] q_{e}(\theta)(1-\phi) q_{I}(\theta) \frac{\partial \xi_{K B}}{\partial \Delta u_{F}}}{\left(q_{e}(\theta)(1-\phi) q_{I}(\theta) \xi_{K B}+q_{e}(\theta) \phi q_{I}(\theta) \xi_{C A}\right)^{2}}
\end{array}
$$

which is positive since both terms are positive. The proves the first part of the corollary. No investor chooses to be a killer if

$$
\left(2 r+\phi q_{I}(\theta)+q_{e}(\theta)\right)(1-\phi) q_{I}(\theta) \xi_{K B} \leq\left(2 r+(1-\phi) q_{I}(\theta)\right) \phi q_{I}(\theta) \xi_{C A}
$$

Since the above solved for $\frac{\partial \omega^{*}}{\partial \Delta u_{F}}>0$ it is easy to see that $\Delta u_{F}$ is not in the numerator of $\frac{\partial \omega^{*}}{\partial \Delta u_{F}}$ and therefore the second derivative of $\omega^{*}$ with respect to $\Delta u_{F}$ is negative everywhere. Therefore, for small enough $\Delta u_{F}$ condition (A-26) holds and no investor chooses to be a killer. Note that condition (A-26) can hold even though $\xi_{K B}>0$ and even though $\phi<1$ so there are projects that create more surplus with a killer as an investor.

ix. Support for extension V.A:

The extension assumes that $\Delta u_{F}=u_{F}(\omega)-u_{E}$, and $\partial u_{F}(\omega) / \partial \omega>0$. Therefore, the sign of $\partial \pi_{K} / \partial \omega$ is no longer deterministic because $\xi_{K B}$ now depends on $\omega$ and thus the profits from being a killer are affected in two ways by an increase in $\omega$.

$$
\pi_{K}=\frac{(1-\phi) q_{I}(\theta)}{2 r+(1-\phi) q_{I}(\theta)+\omega q_{e}(\theta)} \xi_{K B}(\omega)
$$

In the numerator $\xi_{K B}(\omega)$ increases with $\omega$ (i.e., total surplus increases) but the denominator also increase (i.e. competition increases).

However, $\partial \pi_{C} / \partial \omega>0$. That is, the profits from being committed always increase if more investors choose to be killers. This is because

$$
\pi_{C}=\frac{\phi q_{I}(\theta)}{2 r+\phi q_{I}(\theta)+(1-\omega) q_{e}(\theta)} \xi_{C A}
$$

only has $\omega$ in the denominator (with a negative sign) because $\xi_{C A}$ is not effected by $\omega$ (see equation (4)).

Therefore, the Nash equilibria, which we will refer to as the set $\Omega^{*}$, includes all the $\omega^{*}$ such that $\pi_{K}\left(\omega^{*}\right)=\pi_{C}\left(\omega^{*}\right)$ and $\partial \pi_{K} / \partial \omega^{*} \leq \partial \pi_{C} / \partial \omega^{*}$. That is, as long as increasing the fraction of killers increases killer profits, but committer profits increase by the same or more, then no investor will want to change on the margin.

Furthermore, the end points $\left(\omega^{*}=1\right.$ or $\left.\omega^{*}=0\right)$ if $\pi_{K}(1)>\pi_{C}(1)$ or $\pi_{K}(0)>\pi_{C}(0)$.

Note first that it is possible that both $\pi_{K}(1)>\pi_{C}(1)$ or $\pi_{K}(0)>\pi_{C}(0)$ and thus that both $\omega^{*}=1$ and $\omega^{*}=0$ are equilibria. This would occur for example if the profits from being a killer are less than a committer, if all investors are committers, but killer profits always increase as more investors become killers $\partial \pi_{K} / \partial \omega>0$ until it is above the profit from being committed when all investors are killers. In this case both extremes are 
equilibria and no other point is an equilibria.

It is also possible that there are many points that are Nash equilibria. All that is required is an $\omega$ such that a change in the fraction of investors on the margin is not beneficial to the changing investor. We can find all points $\pi_{K}\left(\omega^{*}\right)=\pi_{C}\left(\omega^{*}\right)$

$$
\frac{(1-\phi) q_{I}(\theta)}{2 r+(1-\phi) q_{I}(\theta)+\omega q_{e}(\theta)} \xi_{K B}(\omega)=\frac{\phi q_{I}(\theta)}{2 r+\phi q_{I}(\theta)+(1-\omega) q_{e}(\theta)} \xi_{C A}
$$

and

$$
\begin{aligned}
-\frac{(1-\phi) q_{I}(\theta) q_{e}(\theta)}{\left(2 r+(1-\phi) q_{I}(\theta)+\omega q_{e}(\theta)\right)^{2}} \xi_{K B}(\omega)+ & \frac{(1-\phi) q_{I}(\theta)}{2 r+(1-\phi) q_{I}(\theta)+\omega q_{e}(\theta)} \frac{\partial \xi_{K B}(\omega)}{\partial \omega} \\
& \leq \frac{\phi q_{I}(\theta) q_{e}(\theta)}{\left(2 r+\phi q_{I}(\theta)+(1-\omega) q_{e}(\theta)\right)^{2}} \xi_{C A}
\end{aligned}
$$

Remember that

$$
\xi_{K B}=p_{1} V_{S} E\left[p_{2} \mid S\right]-2\left(u_{O}-u_{E}\right)+\left(1-p_{1}\right) \Delta u_{F}-p_{1} Y(1+r)-X(1+r)^{2} .
$$

So

$$
\frac{\partial \xi_{K B}}{\partial \omega}=\left(1-p_{1}\right) \frac{\partial u_{F}(\omega)}{\partial \omega}
$$

Thus,

$$
\begin{aligned}
-\frac{(1-\phi) q_{I}(\theta) q_{e}(\theta)}{\left(2 r+(1-\phi) q_{I}(\theta)+\omega q_{e}(\theta)\right)^{2}} \xi_{K B}(\omega)+ & \frac{(1-\phi) q_{I}(\theta)}{2 r+(1-\phi) q_{I}(\theta)+\omega q_{e}(\theta)}\left(1-p_{1}\right) \frac{\partial u_{F}(\omega)}{\partial \omega} \\
& \leq \frac{\phi q_{I}(\theta) q_{e}(\theta)}{\left(2 r+\phi q_{I}(\theta)+(1-\omega) q_{e}(\theta)\right)^{2}} \xi_{C A}
\end{aligned}
$$

And we can see that the inequality is true when $\frac{\partial u_{F}(\omega)}{\partial \omega}$ is small, but may not hold at all points where $\pi_{K}\left(\omega^{*}\right)=\pi_{C}\left(\omega^{*}\right)$. Essentially the only equilibria are points where $\pi_{K}\left(\omega^{*}\right)$ crosses $\pi_{C}\left(\omega^{*}\right)$ from above or is tangent from below. 